\title{
Wind Power Ramps Analysis for High Shares of Variable Renewable Generation in Power Systems
}

\author{
M. Saber Eltohamy ${ }^{1}$, M. Said Abdel Moteleb ${ }^{2}$, Hossam Talaat ${ }^{3}$, S. Fouad Mekhemar ${ }^{4}$, Walid Omran ${ }^{5}$ \\ ${ }^{1}$ Department of Power Electronics and Energy Conversion, Electronics Research Institute (postgraduate student at Ain \\ Shams University), Egypt \\ ${ }^{2}$ Department of Power Electronics and Energy Conversion, Electronics Research Institute, Egypt \\ ${ }^{3,4}$ Department of Electrical Engineering, Future University in Egypt, Egypt \\ ${ }^{5}$ Department of Electrical Engineering, Future University in Egypt (on leave from Ain Shams University), Egypt
}

\begin{abstract}
Article Info
Article historys:

Received Dec 10, 2019

Revised Jun 18, 2020

Accepted Jun 29, 2020

\section{Keywords:}

Wind power

Ramp event

Variable renewable generation

Energy management

ABSTRACT

Power system operators should be provided with more information on the characteristics of variable generation power ramps because, although there has been an improvement in the forecasting of wind power, the percentage of error in forecasting is still high to some extent. As a result of the ongoing rise in the participation rate of variable generation, this error will have a significant impact on the balance of power generation and consumption. From the grid operators' viewpoint, in order to balance these ramp events, it is important to get the scale of ramp events in the system as well as the times during which collective events are most likely to arise in order to achieve flexibility and reliability in the power system. Digitization of power systems brings big data which opening opportunities for improving the efficiency of power system operation. This paper analyzes the historical data of powertime curve in two directions: vertical and horizontal, in order to gain details on the behavior of wind power ramps. The method of analysis will be demonstrated by an analysis of actual historical output power of aggregated Belgian wind farms every 15 minutes in 2017 and 2018. Comparing the results of the two years outlined that there are fixed percentages related to wind power ramping behavior and even if the wind capacity is increased, it is possible to determine the extent of these ramps.
\end{abstract}

Copyright () 2019 Institute of Advanced Engineering and Science. All rights reserved.

\footnotetext{
Corresponding Author:

Mohammed Saber Eltohamy,

Department of Power Electronics and Energy Conversion,

Electronics Research Institute,

Joseph Tito St, Huckstep, Qism El-Nozha, Cairo Governorate, 12622, Egypt.

Email: mohammed_saber@eri.sci.eg
}

\section{INTRODUCTION}

The flexibility of the power system is the power system's ability to accommodate both the rapid variation in renewable generation production and the forecast errors [1][2]. A flexible power system is capable of responding rapidly within limits to large changes in demand and supply, both predicted and unforeseen variations and events [3]. However, a precise quantification of power system flexibility is still under research [4]. The growing insertion of variable renewable generation (VRG) into power systems raises the concern that these systems may have not adequate flexibility for balancing the power ramps in VRG, because the power system may has sufficient generating resources to meet the aggregate system demand but these resources have not the power ramping capability to balance inter-hour changes. In Texas, as a result of wind generation, the net load (the remaining load not served by VRG [5][6]) standard deviation increased by $5 \%$ above the load alone [7]. In [8], the characteristics of the variability of wind power in many countries have been studied on the basis of real data over a period of several years, in which the one-hour power ramps 
may be close to $30 \%$ of the nominal capacity in some regions. In [9], the variability of different renewable energy resources (wind, solar, and wave power) was studied by calculating the reserve requirements.

Efforts are done continuously to improve methods and time of wind prediction [10]. However, the percentage of forecasting error is still relatively high even for hour-ahead forecasting [11], which significantly affects the balance between the power generated and consumed especially with the existence of high shares of VRG. In Belgium, an offshore wind integration study concluded that the forecast of wind generation is not enough to predict power ramp events and that detailed analysis is actually required [12]. Figure 1 shows the occurrence of major prediction errors in both magnitude and direction even with shortterm predictions of wind-power forecasting in Belgium [13].

Although wind and PV generations rely largely on wind speed and solar irradiance respectively, the variations in wind speed and solar irradiance can not fully reflect the power variability [14][15]. The explanation of ramp events occurrence by weather changes was studied in order to understand the weather patterns that causes ramp events. Nevertheless, the relationship of ramp events to weather phenomena is an extremely case-dependent issue [16][17]. The authors claimed in [18] that the ramp-up events occur mostly from May to July and ramp-down events from August to January, whereas it was found in [19] that both upward and downward ramp events occurred mostly in months from March to August. In [20], only 34\% of ramp events was induced by frontal passages and thunderstorms phenomena, while a high percentage of ramp events could not be explained. As a result, the power system operators should have information about the wind power ramping characteristics in the system. This information includes the range of ramp events, the type (upward or downward) and the expected occurrence time, which can be obtained from historical databases by statistical analysis. According to this information, the power system operator takes the necessary precautions to avoid problems that could occur in the event of a major prediction error.

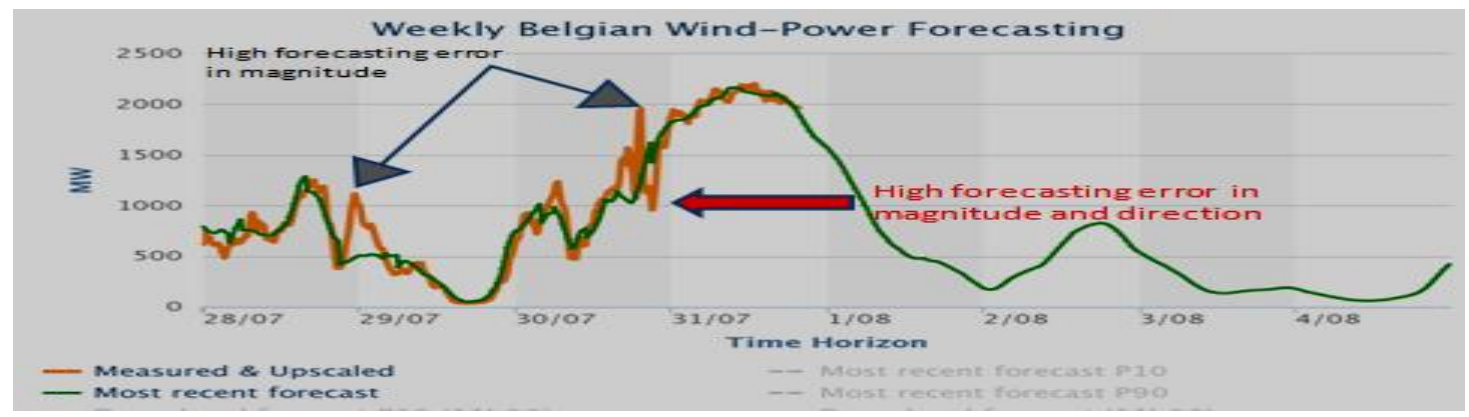

Figure 1. Weekly Belgian wind power forecasting [13]

\section{DEFINITIONS OF WIND POWER RAMP EVENT}

The power ramp $(\Delta p)$ is described as a ramp event if a significant power change occurred in a short period of time [21][10][11], which may cause grid management problems [12], so the magnitude, direction, and duration of the power change should be determined to define the ramp event [22]. The ramp direction can be upward or downward, while the ramp event magnitude is usually determined as a percentage from the installed capacity $\left(P_{R}\right)$ or as a value of megawatts $(M W)$ that depends on the studied system [19][23]. The ramp event magnitude is chosen to reflect the amount of power change that is difficult to be handled in the given time interval. In practice, it is selected based on inputs from system operators; it can vary from one region to another, and it can also vary for the same region over the years to match the changes in load demand and generation mix. While the ramp duration $(\Delta t)$ is a user-defined parameter which defines the time interval (minutes or hours) considered for ramp identification.

In [24], the different definitions of ramp event in wind power, solar power, net load, and load were summarized; in which the threshold value of ramp event magnitude was determined by different percentages that ranged from $10 \% P_{R}$ to $75 \% P_{R}$, whereas the threshold value of ramp duration extended from five minutes to six hours. In [14], the authors studied the variability of wind power at different time intervals, starting from 5 minutes to 1 hour with their corresponding thresholds from $1 \% P_{R}$ to $15 \% P_{R}$ respectively. In view of that, there is no consensus on a precise definition for the ramp event yet. This great difference in defining the ramp event is due to the difference between the power systems in characteristics and the flexibility available to meet these ramps [25]. In VRG, the downward ramp events are to some extent more difficult to be managed than upward. This is because the upward ramps can be managed by adjusting other generators' schedules, or curtailment of VRG if necessary, but when the downward ramps occurred, the system operators have to compensate the power deficit by increasing the output power from the remaining online generators or finding other generation to compensate this power deficit and keep the load balanced. Thus, a lower threshold value

Wind Power Ramps Analysis for High Shares of Variable Renewable Generation (M. Saber Eltohamy et al) 
or percentage was selected for down-ramps than that of up-ramps [26][27][28]. In the next section, the analysis procedures of VRG historical data will be explained. By this analysis, the power system planner or operator can get the necessary information about the characteristics of power ramps that occurred in the selected time interval.

\section{ANALYSIS PROCEDURES}

The analysis of the power-time curve of VRG historical data will take two directions based on the time-axis of the power signal time series, which are vertical and horizontal analysis as follows:

\subsection{Vertical analysis of time series}

In which the power ramping behavior at each observation time $(t)$ in the power signal time series is studied separately in detail by using the historical readings of power ramps at that observation time, then moving to the next one until finishing all observation points at the power signal time series as follows:

- The historical ramp readings $\left(\Delta p_{n}\right)$ that occurred during the studied time interval $(\Delta t)$ at observation time $(\mathrm{t})$ are calculated as in "(1)":

$\Delta p_{n}=P(t+\Delta t)-P(t), \boldsymbol{n}=(1, \ldots, N)$

Where $n$ is a counter for the number of historical readings and $N$ is the total number of historical readings that may be taken for certain days in the year (i.e. weekends), month, season or year. For example, the historical ramp readings for a studied year (i.e. $\mathrm{N}=365$ ) which occurred at observation time $\mathrm{t}=4 \mathrm{PM}$ within the studied time period $\Delta \mathrm{t}=30$ minutes are given by: $\Delta p_{n(1: 365)}=p(4: 30)-p(4)$. The studied time interval $\Delta \mathrm{t}$ is chosen by the system operator according to the studied operating stage. The positive value of $\Delta p_{n}$ refers to ramp-up, while the negative refers to ramp-down as follow:

$\Delta p_{n}>0 \rightarrow \operatorname{Ramp}-u p \uparrow$,

$\Delta p_{n}<0 \rightarrow$ Ramp-down $\downarrow$

- The average value of historical power ramps $\left(\Delta p_{\text {avgt }}\right)$ that occurred within the time period $(\Delta t)$ at observation time $(\mathrm{t})$ is given by "( 3$)^{\prime}$ ” :

$$
\Delta p_{\text {avgt }}=\frac{1}{N} \sum_{n=1}^{N} \Delta p_{n}
$$

The positive average value indicates that the upward power ramps are frequently occurred at observation time t. Conversely, the negative average indicates that the downward power ramps are mostly occurred at that observation time. This gives the power system planners or operators the information about the direction of most frequent ramp at each observation time.

- The standard deviation of historical power ramps at observation time $\mathrm{t}\left(\sigma_{t}\right)$ is as follow:

$$
\sigma_{t}=\sqrt{\frac{1}{N-1} \sum_{n=1}^{N}\left(\Delta \mathrm{p}_{n}-\Delta \mathrm{p}_{\mathrm{avgt}}\right)^{2}}
$$

The standard deviation value shows the spread of power ramps around the average value. If the standard deviation value at observation time $t$ is small, it indicates that the values of historical ramp readings are close to the average value, and the average value can be used to represent the power ramps at that observation time. Whereas the average value does not represent perfectly the power ramps at observation time $t$, if the standard deviation value is high; this means that the power ramps at that observation time are spread out over a wider range.

- The power system operator can get the information of maximum values of historical power ramps that occurred at each observation time $\mathrm{t}$ during the studied period $\Delta \mathrm{t}$ as follow:

$$
\begin{aligned}
& \Delta p_{\text {maxt }} \uparrow=\max \Delta \mathrm{p}_{n} \\
& \Delta p_{\text {maxt }} \downarrow=\min \Delta \mathrm{p}_{n}, \mathrm{n}=(1, \ldots, \mathrm{N})
\end{aligned}
$$

Where $\Delta p_{\text {maxt }} \uparrow$ is the maximum ramp-up value and $\Delta p_{\text {maxt }} \downarrow$ is the maximum ramp-down value

- The ramping range is the difference between the maximum value of upward and downward power ramps, which is given by "(6)":

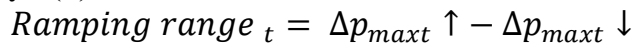

Where Ramping range ${ }_{t}$ is the ramping range of historical power ramps that occurred at observation time $\mathrm{t}$ during the studied period $\Delta \mathrm{t}$.

After completing the calculations at observation time $t$, we move to the next observation time in the power signal time series. The next observation time $(t+\Delta t)$ is taken as the new observation time $t$, and the calculations are repeated until reaching $\mathrm{t}=24 \mathrm{~h}$. 


\subsection{Horizontal analysis of time series}

In which the daily historical readings of power ramps that occurred throughout each day are studied to get the information about the power ramping behavior in certain weeks, months, seasons or years during the studied time interval $\Delta \mathrm{t}$ as follows:

- The historical ramp readings that occurred during the studied time interval $(\Delta t)$ in a studied day are given by "7":

$$
\begin{aligned}
& \Delta p_{t}=P(t+\Delta t)-P(t), \mathrm{t}=(1, \ldots, h) \\
& \Delta p_{t}>0 \rightarrow \text { Ramp-up } \uparrow \\
& \Delta p_{t}<0 \rightarrow \text { Ramp-down } \downarrow
\end{aligned}
$$

Where $\Delta \mathrm{p}_{\mathrm{t}}$ is the power ramp at time $\mathrm{t}$ and $\mathrm{h}$ is the length of the power curve time series.

- The average value of historical power ramps in the studied day $\left(\Delta \mathrm{p}_{\mathrm{avgd}}\right)$ that occurred at the studied time interval $\Delta \mathrm{t}$ and the standard deviation $\left(\sigma_{\mathrm{d}}\right)$ are obtained by "(8)","(9)":

$$
\begin{aligned}
& \Delta p_{\text {avgd }}=\frac{1}{h} \sum_{t=1}^{h} \Delta p_{t} \\
& \sigma_{d}=\sqrt{\frac{1}{h-1} \sum_{t=1}^{h}\left(\Delta p_{t}-\Delta p_{\text {avgd }}\right)^{2}}
\end{aligned}
$$

- The maximum values of power ramps at the studied day are given by "(10)":

$\Delta p_{\max d} \uparrow=\max \Delta p_{t}$

$\Delta p_{\text {maxd }} \downarrow=\min \Delta p_{t}, \mathrm{t}=(1, \ldots, h)$

Where $\Delta \mathrm{p}_{\text {maxd }} \uparrow$ is the maximum ramp-up value and $\Delta \mathrm{p}_{\text {maxd }} \downarrow$ is the maximum ramp-down value.

- The ramping range throughout the day during the studied time period $\Delta t$ is given by "(11)":

Ramping range $_{d}=\Delta p_{\text {maxd }} \uparrow-\Delta p_{\text {maxd }} \downarrow$

- The ramping behaviour in a weak, month, season, or a year ago can be given by “(12)”:

$$
\begin{aligned}
& \text { his } \Delta p_{\text {avgd }}=\frac{1}{d_{n}} \sum_{d_{1}}^{d_{n}} \Delta p_{\text {avgd }} \\
& \text { his } \Delta p_{\text {maxd }} \uparrow=\left.\max \right|_{d_{1}} ^{d_{n}} \Delta p_{\text {maxd }} \uparrow \\
& \text { his } \Delta p_{\text {maxd }} \downarrow=\left.\min \right|_{d_{1}} ^{d_{n}} \Delta p_{\text {maxd }} \downarrow
\end{aligned}
$$

Where his $\Delta \mathrm{p}_{\text {avgd }}$ is the average value of power ramps over a certain number of days, his $\Delta \mathrm{p}_{\operatorname{maxd}} \uparrow \downarrow$ represent the maximum ramp-up and ramp-down values of historical power ramps over a certain number of days and $d_{n}$ is the total number of days i.e. for a week, month and year, $d_{n}=7,30$ and 365 respectively.

\section{FREQUENCY OF POWER RAMPS}

The number of occurrence of an event is called the frequency of that event, while the relative frequency of an event can be determined by dividing its frequency by the total number of data points in the sample. For separate events, the sum of their relative frequencies should be equal to 1 . The heights of the relative frequency histogram are interpreted as probabilities. The information about the occurrence probability of a certain type of power ramps can be obtained as follows:

$$
P\left(E_{i}\right)=\frac{E_{i}}{E}
$$

Where $P\left(E_{i}\right)$ is the occurrence probability of a certain type (i) of power ramps, $\mathrm{E}_{\mathrm{i}}$ is the number of occurrence of that type and $\mathrm{E}$ is the total number of historical readings.

\section{CASE STUDY}

In Belgium, nearly $50 \%$ of electricity is produced by the nuclear energy that is planned to be phased out before 2026 for achieving the decarbonisation target. As a result, the share of renewable generation is rapidly growing to be an important part of Belgium's energy mix. The actual variations within a time interval of 15 minutes $(\Delta t=15 \mathrm{~min})$ in the production of Belgium's aggregated wind farms in 2017 and 2018 are analyzed by the above analysis procedures [13]. If the power ramp exceeds $5 \% P_{R}$, it is considered a ramp event, where the average installed wind capacity in 2017 was $2.44 \mathrm{GW}$ with a maximum installed capacity of $2.62 \mathrm{GW}$. While in 2018, the average installed wind capacity was $2.92 \mathrm{GW}$ with a maximum installed capacity of $3.16 \mathrm{GW}$. 


\subsection{Vertical analysis results and discussion}

A comparison of maximum ramp-down of power in 15min interval at each observation time in 2017 and 2018 is showed in Figure 2. The two curves seem to be close to each other and have nearly the same values at many observation times, as in 1:45, 7:15, 7:30, 11:45, 16:30, 19:00, 20:45 and 22:00. The average values of maximum downward power ramps that occurred in a time interval of 15 min in 2017 and 2018 are 194.32 MW and 211.62 MW respectively, representing $7.97 \%$ and $7.24 \%$ of the average installed wind capacity in 2017 and 2018 respectively. While the average value of maximum downward power ramps increases with increasing the installed wind capacity, its ratio to the average installed wind capacity approximately remains constant. The maximum downward power ramps overall observation times range from 93.43 to $654.84 \mathrm{MW}$ in 2017 , representing $3.83 \%$ to $26.8 \%$ of the average installed wind capacity in 2017; while in 2018, they range from 106.59 to $455.86 \mathrm{MW}$, representing $3.65 \%$ to $15.6 \%$ of the average installed wind capacity in 2018. While the two ranges are different, the lowest values in both ranges are approximately equal when each value is compared to the average installed wind capacity in its year.

A Comparison of maximum ramp-up of power in $15 \mathrm{~min}$ interval at each observation time in 2017 and 2018 is showed in Figure 3. The two curves seem to be close to each other and nearly have the same values at many observation times, as in 00:00, 1:30, 2:30, 2:45, 5:30, 7:00, 7:15, 8:00, 9:30, 9:45, 11:45, 12:30, 14:00, 19:00 and 22:45. The average values of maximum upward power ramps in 2017 and 2018 are 184.96 MW and 224.46 MW, representing $7.58 \%$ and $7.68 \%$ of the average installed wind capacity in 2017 and 2018 respectively, which are nearly equal. Therefore, the average value of maximum upward power ramps increases with increasing the installed wind capacity, but its ratio to the average installed wind capacity approximately remains constant. The maximum values of upward power ramps overall observation times range from 75.34 to $444.04 \mathrm{MW}$ in 2017 , representing $3.09 \%$ to $18.2 \%$ of the average installed wind capacity; while in 2018 , they range from 103.89 to $736.93 \mathrm{MW}$, representing $3.56 \%$ to $25.2 \%$ of the average installed wind power capacity. While the two ranges are different, the lowest values of the two ranges are approximately equal when each value is compared to the average installed wind capacity in its year. Thus, by vertical analysis, the power system operator can easily obtain the information about the range of maximum power ramps in the two directions that occurred within the studied time interval at each observation time.

A comparison of the average values of power ramps in $15 \mathrm{~min}$ interval at each observation time in 2017 and 2018 is shown in Figure 4, in which the two curves are nearly identical. In both years, the average value of power ramps has a maximum value and transformed from a maximum ramp down value to a maximum ramp up value in the duration between 2:45 to 3:30 AM. The average value of power ramps tends to be a ramp-up in the period from 11:00 to 23:00, whereas in the period from 23:00 to 11:00, it tends to be a ramp-down. The average values of power ramps overall observation times range from -7.77 to $8.2 \mathrm{MW}$ in 2017; while in 2018, they range from -25.97 to 16 MW. For most observation times, the average values of power ramps are nearly equal to zero, which exhibits the fluctuations of wind power between up and down ramps all the day times. Consequently, the average value of power ramps should not be taken to represent the actual variation in wind power.

A comparison of the standard deviation of power ramps at each observation time in 2017 and 2018 is showed in Figure 5. In 2017, the standard deviation values ranged from 28.4 to $47.66 \mathrm{MW}$, while in 2018, they ranged from 35.68 to $56.3 \mathrm{MW}$. The average values of the standard deviation in 2017 and 2018 are 36.55 MW and 41.9 MW respectively, representing $1.499 \%$ and $1.43 \%$ of the average installed wind capacity, which are approximately equal. Thus, while the average value of the standard deviations increased with increasing the installed wind capacity, its ratio to the average installed wind capacity remains constant. Additionally, the difference between the upper and lower values in the standard deviation range remains constant. A comparison between the standard deviation and the average power ramp at each observation time in 2017 and 2018 is showed in Figure 6, which illustrates that the standard deviation in both years is very high compared to the average power ramp. This comparison also confirms that the average value of the power ramps should not be used to represent the actual power ramps in wind power.

In Figure 7, a comparison of ramping range of power ramps in $15 \mathrm{~min}$ interval at each observation time $\mathrm{t}$ for years 2017 and 2018 is shown. The ramping range in 2017 ranged from 212.11 to 793.17 MW, representing $8.7 \%$ to $32.5 \%$ of the average installed wind capacity; while in 2018, it ranged from 235.66 to 929.23 MW, representing $8.1 \%$ to $31.8 \%$ of the average installed wind capacity, respectively. In the two years, the upper and lower percentages of the ramping range are approximately equal. The average value of ramping range overall observation times in 2017 is $379.28 \mathrm{MW}$, representing $15.5 \%$ of the average installed wind capacity; while in 2018, it is $436.08 \mathrm{MW}$, representing $15 \%$, which is approximately the same as in 2017. Thus, while the average value and the scale of ramping range increase with increasing the installed wind capacity, the ratio of these values to the average installed wind capacity remains constant.

A comparison of the relative frequency of upward power ramps in $15 \mathrm{~min}$ interval at each observation time t for years 2017 and 2018 is showed in Figure 8. The two curves seem to have the same 
values in the most observation times. The relative ramp-up frequency is more than $50 \%$ in the period from 11 $\mathrm{AM}$ to $11 \mathrm{PM}$ and it is less than 50\% in the period from $11 \mathrm{PM}$ to $11 \mathrm{AM}$. While the opposite happens in Figure 9, where the relative ramp-down frequency is less than $50 \%$ in the period from $11 \mathrm{AM}$ to $11 \mathrm{PM}$ and it is approximately more than $50 \%$ in the period from $11 \mathrm{PM}$ to $11 \mathrm{AM}$. Therefore the relative ramp-up frequency is more than ramp-down frequency in the period from $11 \mathrm{AM}$ to $11 \mathrm{PM}$, whereas the relative ramp-down frequency is more than ramp-up frequency in the period from $11 \mathrm{PM}$ to $11 \mathrm{AM}$, comparing these results with Figure 4 and Figure 14, where in Figure 4, the average value of power ramps tends to be a rampup from $11 \mathrm{AM}$ to $11 \mathrm{PM}$ and a ramp-down from 11 PM to $11 \mathrm{AM}$. While in Figure 14, the average ramp that is obtained by horizontal analysis for all months is nearly zero. In the duration from 3:00 AM to 3:30 $\mathrm{AM}$, a quick change happened from a relatively high ramp-down frequency at 3:00 AM to a relatively high ramp-up frequency at 3:30 AM, see Figures 8, 9; this quick change appears also in Figure 4. In the two years, the average number of upward and downward power ramps overall observation times is approximately 180 and 184 respectively.

A comparison between the numbers of downward ramp events that happened in the period of $15 \mathrm{~min}$ interval at each observation time $t$ in 2017 and 2018 is presented in Figure 10. The number of ramp-down events in both years is high at the following observation times: 1:00, about 3:00, 5:00, 10:45, 12:00, and 16:30-23:45. The ramp-down events are scarcely happening in the period from 12:30 to 14:45. In the two years, the numbers of ramp-down events in the period from 16:00 to 6:00 are higher than that from 6:00 to 16:00. In 2017, the average number of ramp-down events is 2.2 , while in 2018 , it is 1.88 . Consequently, the average number of ramp-down events decreased while the installed wind capacity increased.

In Figure 11, a comparison between the numbers of upward ramp events that happened in the period of 15 min interval at each observation time $t$ in 2017 and 2018 is presented. The number of ramp-up events in both years is high at the following observation times: 3:30, 10:30-10:45, 12:45, 14:45, and 21:30. In the period from 8:00 to 9:45 AM, the ramp-up events are scarcely happening. The average number of ramp-up events in 2017 is 2.3 , while it is 1.91 in 2018 . Hence, the average number of ramp-up events decreased while the installed wind capacity increased. Table 1 summarizes the vertical analysis results.

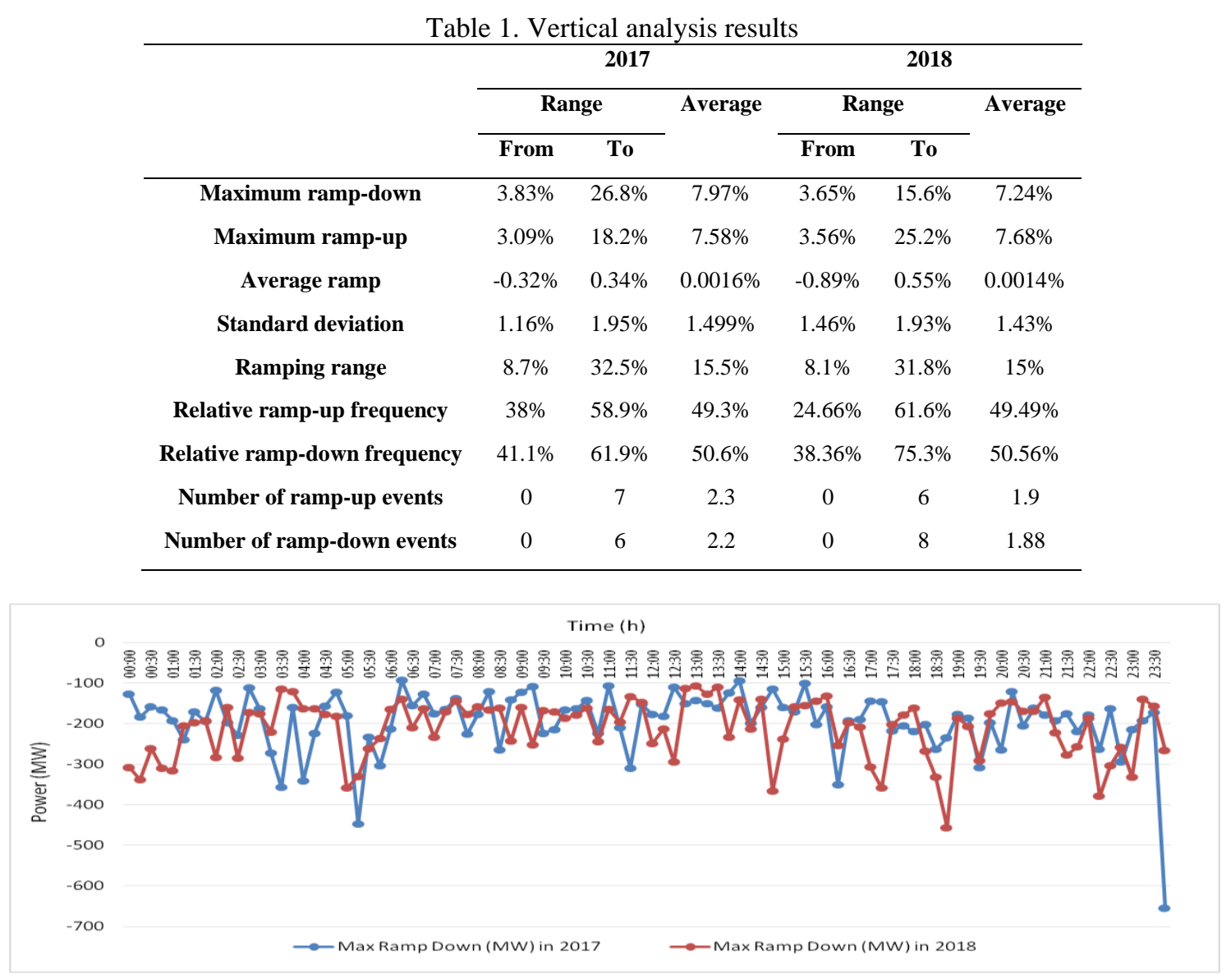

Figure 2. Comparison between maximum ramp-down of power in $15 \mathrm{~min}$ interval at each observation time for the years 2017 and 2018. 


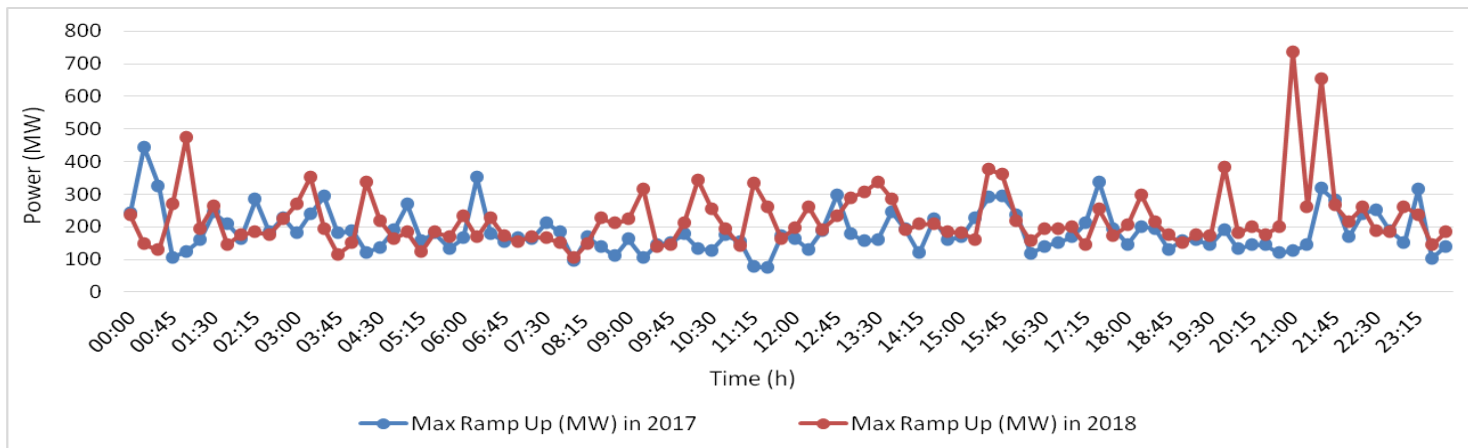

Figure 3. Comparison between maximum ramp-up of power in $15 \mathrm{~min}$ interval at each observation time for the years 2017 and 2018.

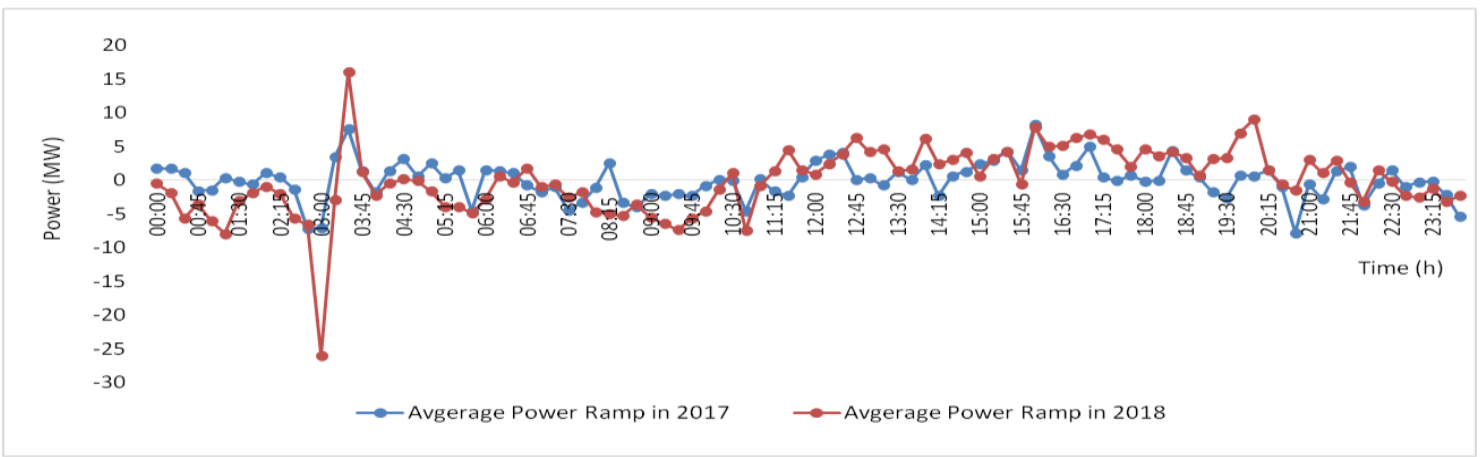

Figure 4. Comparison between average power ramp in $15 \mathrm{~min}$ interval at each observation time for the years 2017 and 2018.

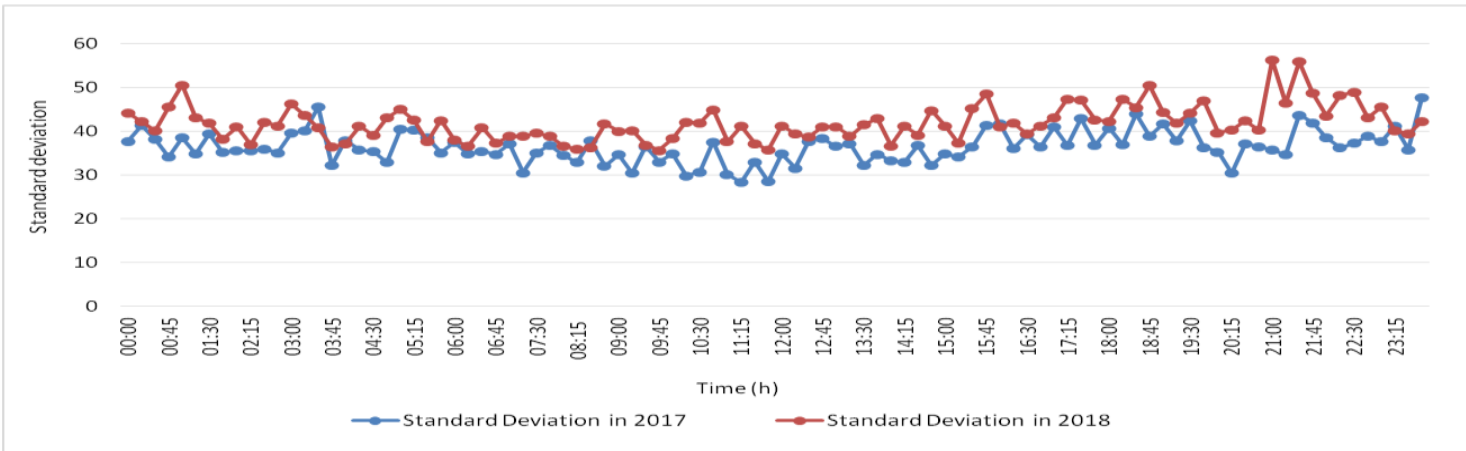

Figure 5. Comparison of the standard deviation at each observation time for the years 2017 and 2018.

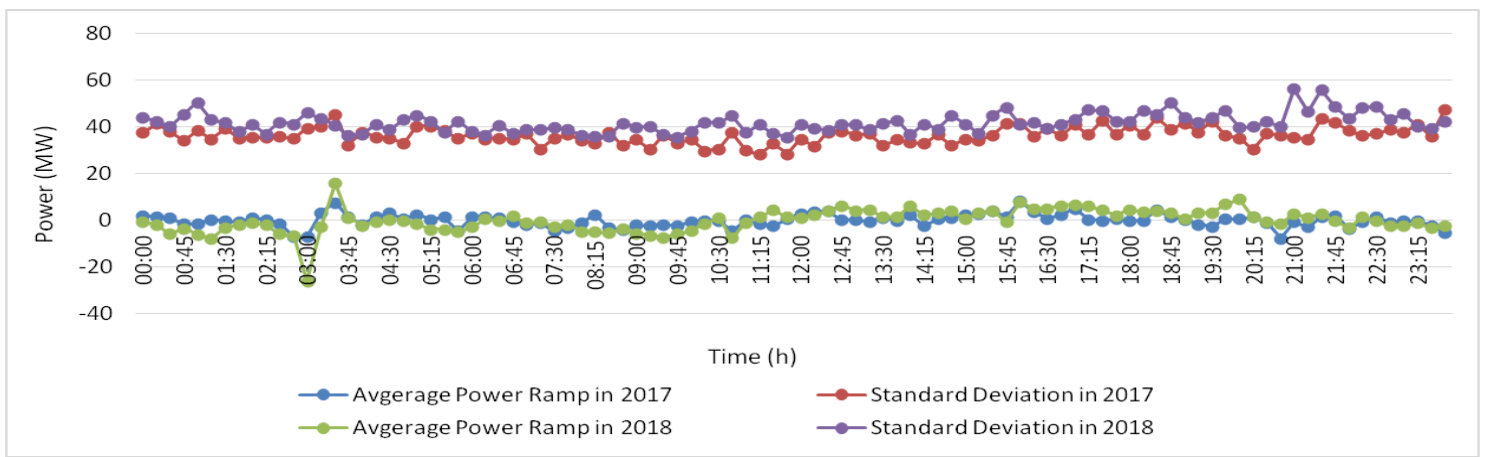

Figure 6. Comparison between the value of standard deviation and the average value of power ramps at each observation time for the years 2017 and 2018. 


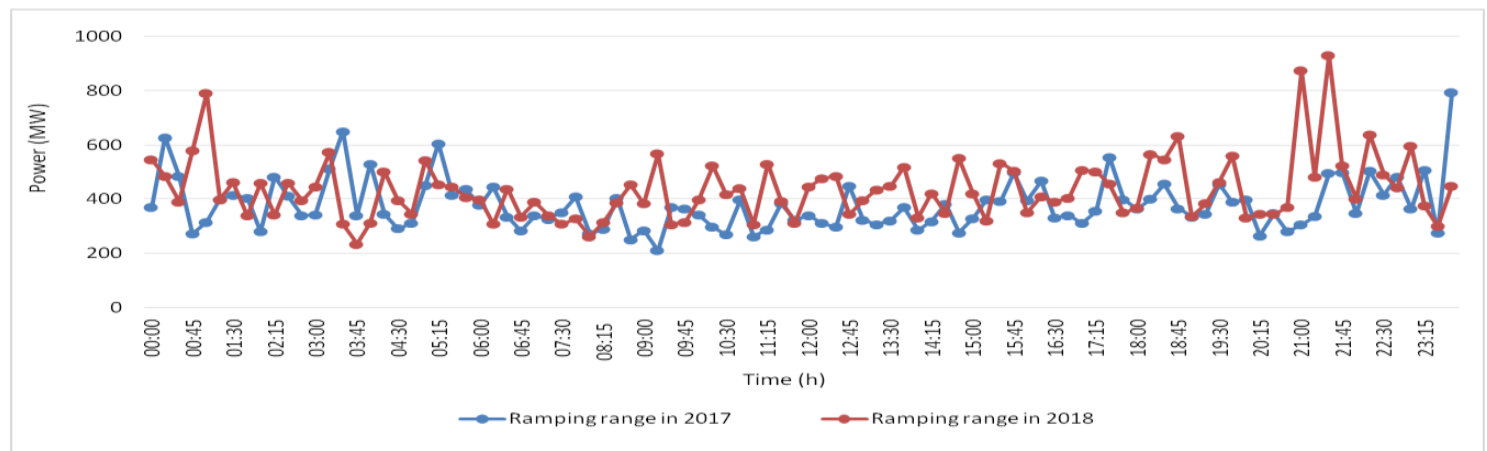

Figure 7. Comparison of ramping range of power ramps in $15 \mathrm{~min}$ interval at each observation time for the years 2017 and 2018.

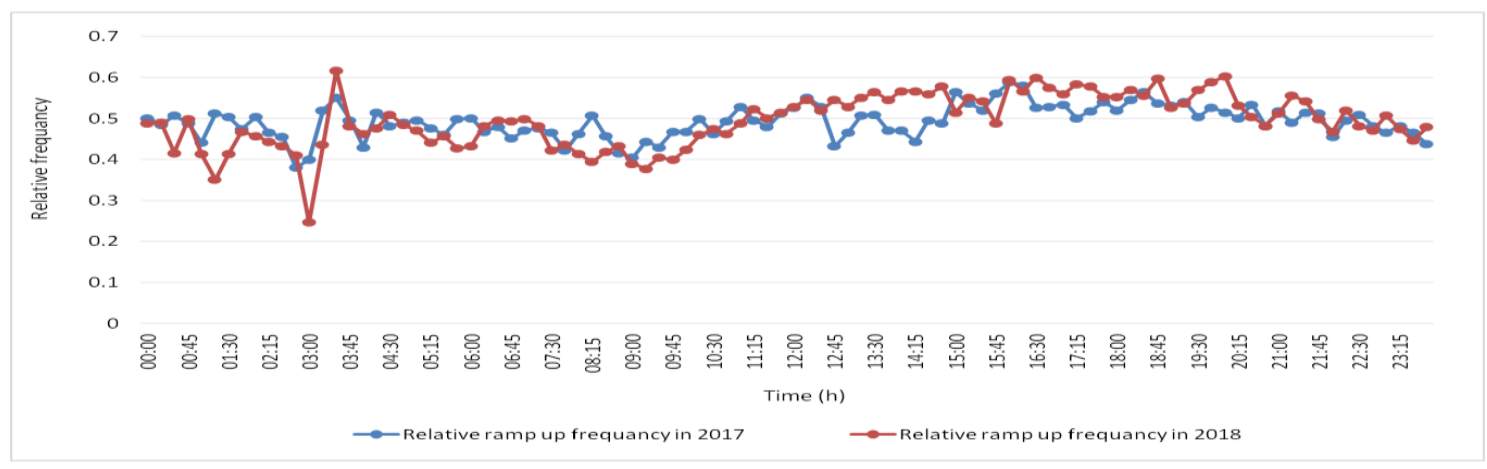

Figure 8. Comparison between the relative frequency of upward power ramps in 15 min interval at each observation time for the years 2017 and 2018.

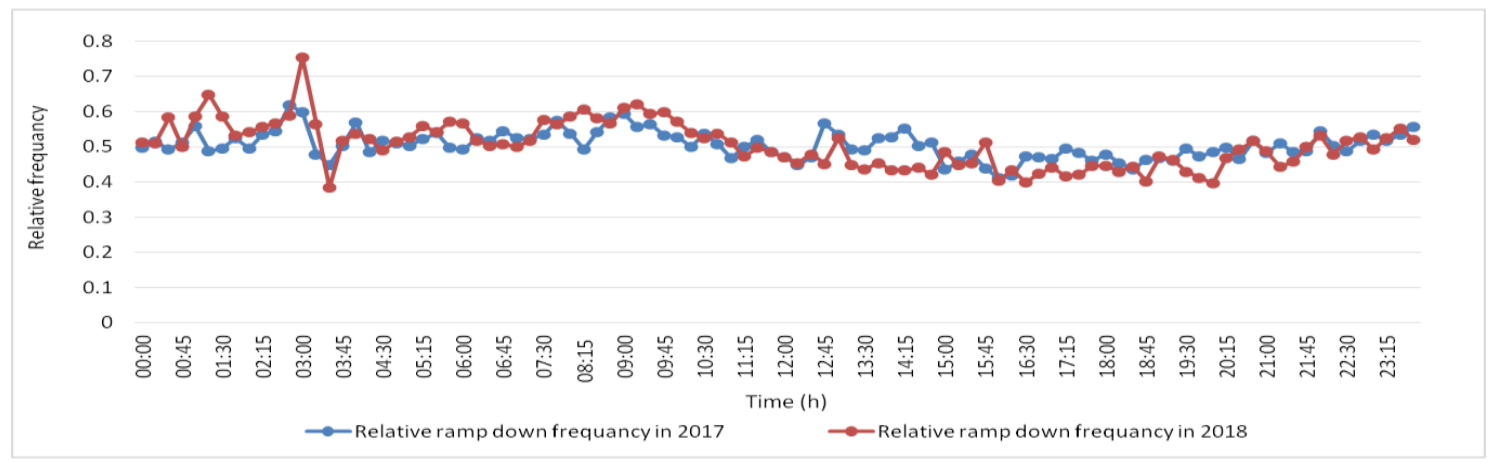

Figure 9. Comparison between the relative frequency of downward power ramps in 15 min interval at each observation time for the years 2017 and 2018.

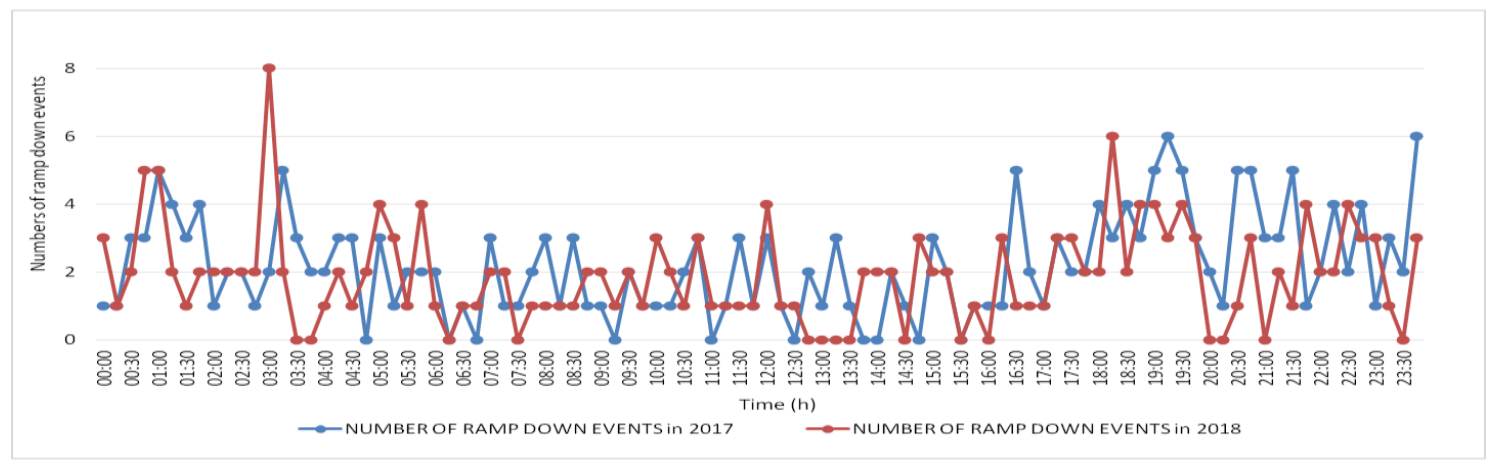

Figure 10. Comparison between the number of downward power ramp events in 15 min interval for each observation time for the years 2017 and 2018. 


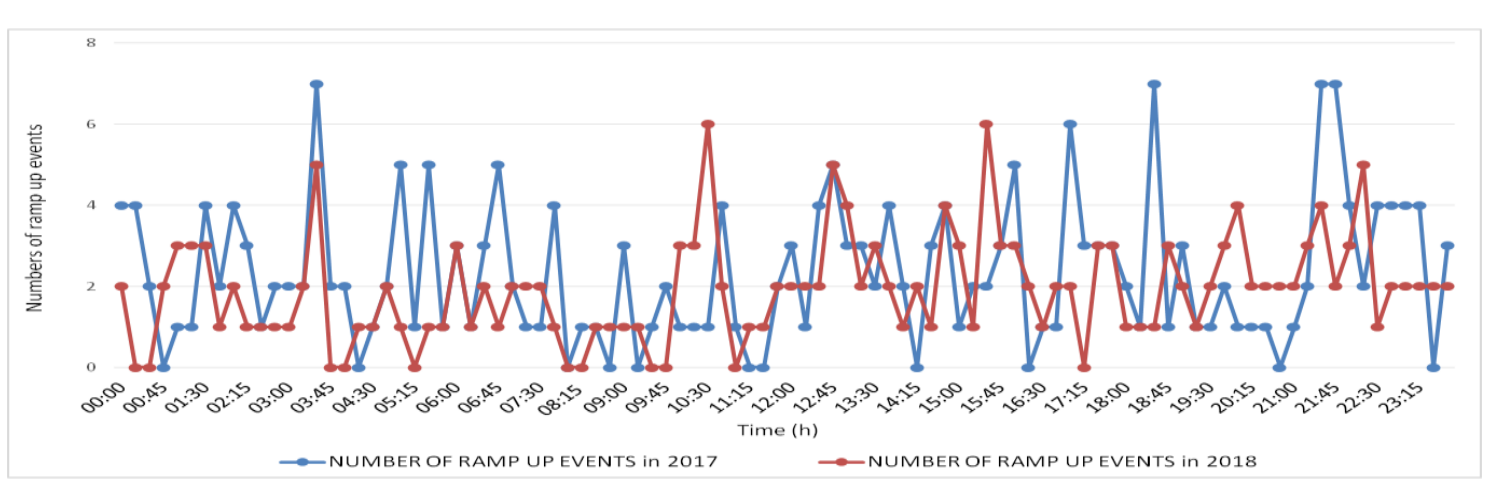

Figure 11. Comparison between the number of upward power ramp events in 15 min interval for each observation time for the years 2017 and 2018.

\subsection{Horizontal analysis results and discussion}

A comparison of the maximum downward power ramps in 2017 and 2018 that occurred in 15min interval for each month is presented in Figure 12. In the two years, the maximum values of downward power ramps are very close to each other in most months except in January, February and June. The average values of maximum downward power ramps overall months in 2017 and 2018 were $317.84 \mathrm{MW}$ and $316.62 \mathrm{MW}$ respectively, representing $13 \%$ and $11 \%$ of the average installed wind capacity, which are close proportions.

A comparison of the maximum upward power ramps in 2017 and 2018 that occurred in 15min interval for each month is presented in Figure 13, where the maximum values of upward power ramps are very close to each other in most months except in January, March, July and August. The highest values of maximum upward power ramps in 2017 occurred in March, December, August and July respectively, while in 2018, they occurred in July, August, January and December respectively. The average values of maximum upward power ramps overall months in 2017 and 2018 were $283.21 \mathrm{MW}$ and $346.49 \mathrm{MW}$, representing $11.6 \%$ and $11.9 \%$ of the average installed wind capacity in 2017 and 2018 respectively, which are approximately equal. Therefore, by horizontal analysis, the power system operator can easily obtain the information about the range of maximum power ramps in the two directions that occurred within the studied time interval for each month or week, if needed.

A comparison of the average values of power ramps in 2017 and 2018 that occurred in a time interval of $15 \mathrm{~min}$ for each month is presented in Figure 14. When comparing the two years, the average values of power ramps are very close to each other in all months and are the same from the point of view whether they represent upward or downward power ramp except in December and August. The average values of power ramps in the two years are very small $(<0.7 \mathrm{MW})$, which exhibit the high fluctuation in wind power.

A comparison of the standard deviation of power ramps that occurred within a time interval of 15min for each month in 2017 and 2018 is showed in Figure 15. When comparing the two years, the standard deviation values of power ramps are very close to each other in all months. The standard deviation values in 2017 ranged from 28.196 to $47.93 \mathrm{MW}$, representing $1.2 \%$ to $1.97 \%$ of the average installed wind capacity, while in 2018, they ranged from 30.51 to $49.02 \mathrm{MW}$, representing $1.04 \%$ to $1.68 \%$ of the average installed wind capacity. In 2017 , the average value of the standard deviations is $36.47 \mathrm{MW}$ and in 2018 , it is 41.93 MW, representing $1.495 \%$ and $1.435 \%$ of the average installed wind capacity respectively, which are approximately equal. Hence, these results confirm the vertical analysis results, where the average value of the standard deviations increased with increasing the installed wind capacity but its ratio to the average installed wind capacity remains constant. In addition, the difference between the upper and lower values in the range of the standard deviation remains constant in the two years.

A comparison of the standard deviation and the average value of power ramps for each month in 2017 and 2018 is showed in Figure 16, which confirms the results obtained by the vertical analysis and presented in Figure 6, where the standard deviation is very high compared to the average power ramp, so the average value of power ramps does not represent the actual power ramps in wind power.

In Figure 17, a comparison of the ramping range of power ramps that occurred within a time interval of $15 \mathrm{~min}$ for each month in 2017 and 2018 is shown. The ramping range in 2017 ranged from 434.86 MW to $969.78 \mathrm{MW}$, representing $17.83 \%$ to $39.76 \%$, respectively, of the average installed wind capacity in that year, while in 2018 , they ranged from $362.21 \mathrm{MW}$ to $1074.92 \mathrm{MW}$, representing $12.4 \%$ to $36.79 \%$, respectively, of the average installed wind capacity. The average values of power ramping range in 2017 and 2018 were $601.04 \mathrm{MW}$ and $663.11 \mathrm{MW}$, representing $24.6 \%$ and $22.7 \%$ of the average installed wind capacity; which are close proportions. 
The relative frequencies of upward and downward power ramps are presented in Figures 18, 19. The relative frequencies of both ramp types (upward and downward) are nearly the same in all months in the two years which reflects on the average, where the average relative frequency of upward power ramps overall months in 2017 and 2018 is 0.493 and 0.495 respectively, while the average relative frequency of downward power ramps overall months in 2017 and 2018 is 0.506 and 0.505 respectively.

The numbers of upward and downward ramp events in 2017 and 2018 are presented in Figures 20, 21. The average number of upward and downward ramp events in 2017 is 18.4 and 17.4, respectively. Whereas the average number of upward and downward ramp events in 2018 is 15.25 and 15 . The results demonstrate that the average number of upward and downward ramp events is nearly equal for the same year. This also appears in Figures 22, 23 when the numbers of ramp-up and down events in 15min interval are compared for each year separately. The results also demonstrate that, while the installed wind capacity increased, the average number of upward and downward ramp events decreased. This is in contrast to the results stated in [26], where the authors studied the ramp events with different penetration levels of renewable generation $(5.45 \%, 9.77 \%, 15.85 \%$, and $51.38 \%)$ but a scaling method was used rather than using actual data, this method was used to scale up the share of renewable based on the measured data of $5.45 \%$ penetration, the optimized swing door algorithm was used for detecting ramp events in different time resolutions. However, the accuracy of detecting the ramp events in wind generation decreased as time resolution decreased.

The authors in [18] claimed that the ramp-up events occur mostly from May to July and ramp-down events from August to January, whereas it was found in [19] that both upward and downward ramp events occurred mostly in months from March to August. However, when the results of the two years are compared, we could not determine certain months for the occurrence of ramp events more than other months, whether the ramp events are up or down, but they occurred in all months in the two years at random. This confirms that the information about the ramp events is an extremely case-dependent issue. In addition, the study of the variability of wind power in a wind farm differs from studying the variability of aggregated wind farms, which may be found in different places. Table 2 summarizes the horizontal analysis results.

Table 2. Horizontal analysis results

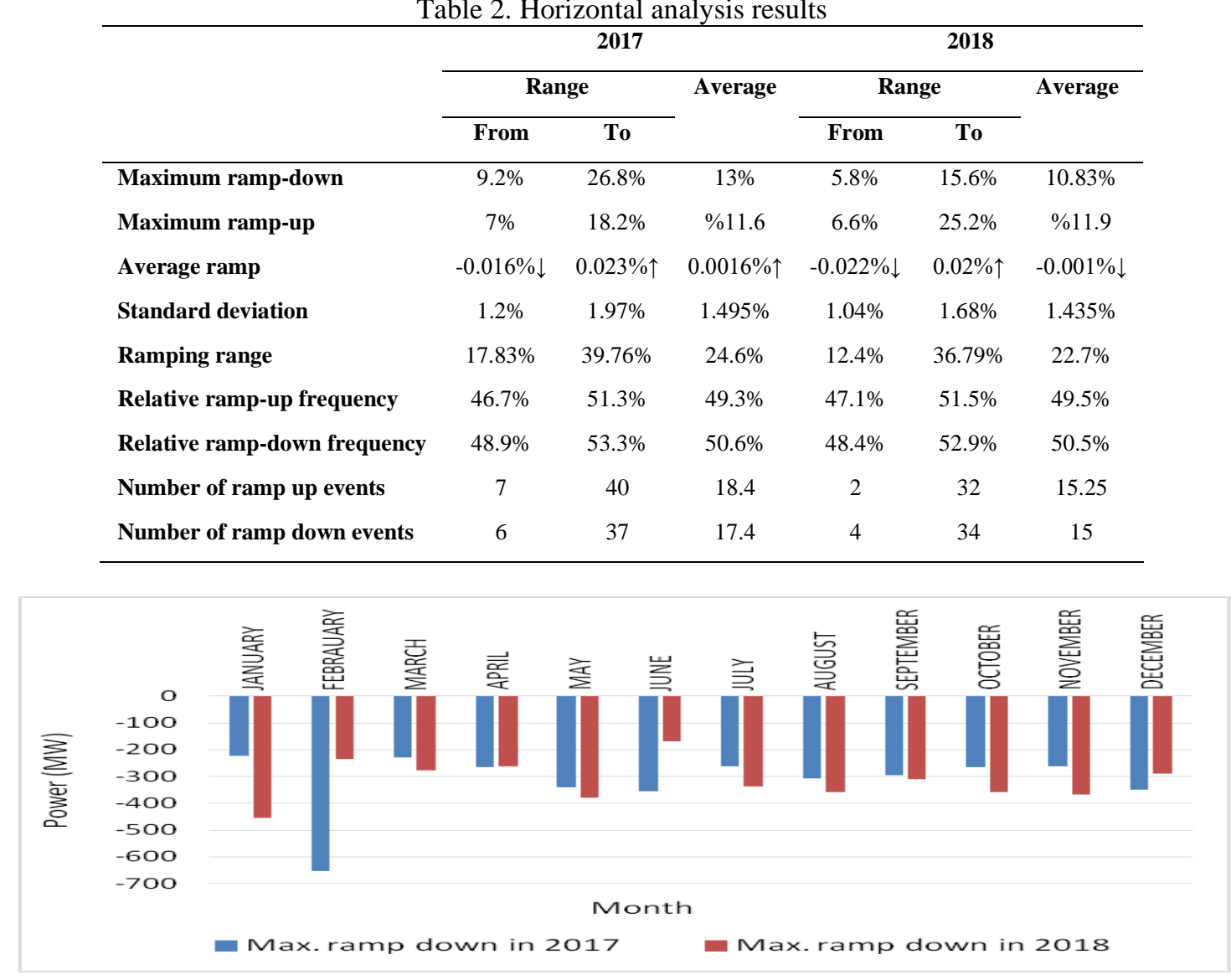

Figure 12. Comparison of the maximum ramp-down in 15min interval for each month in 2017 and 2018. 


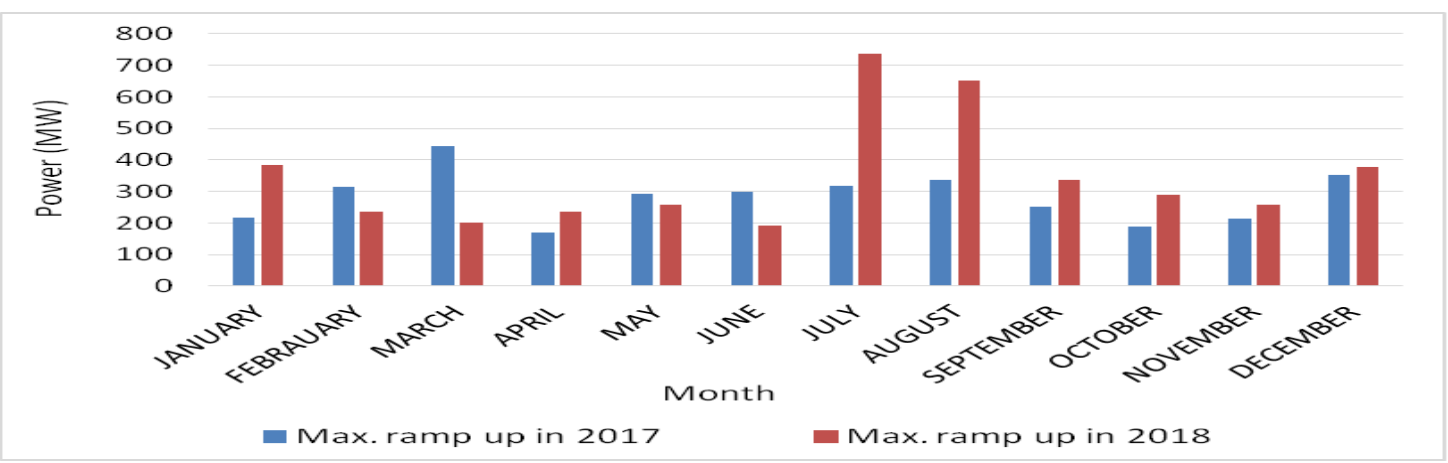

Figure 13. Comparison of the maximum ramp-up in 15min interval for each month in 2017 and 2018.

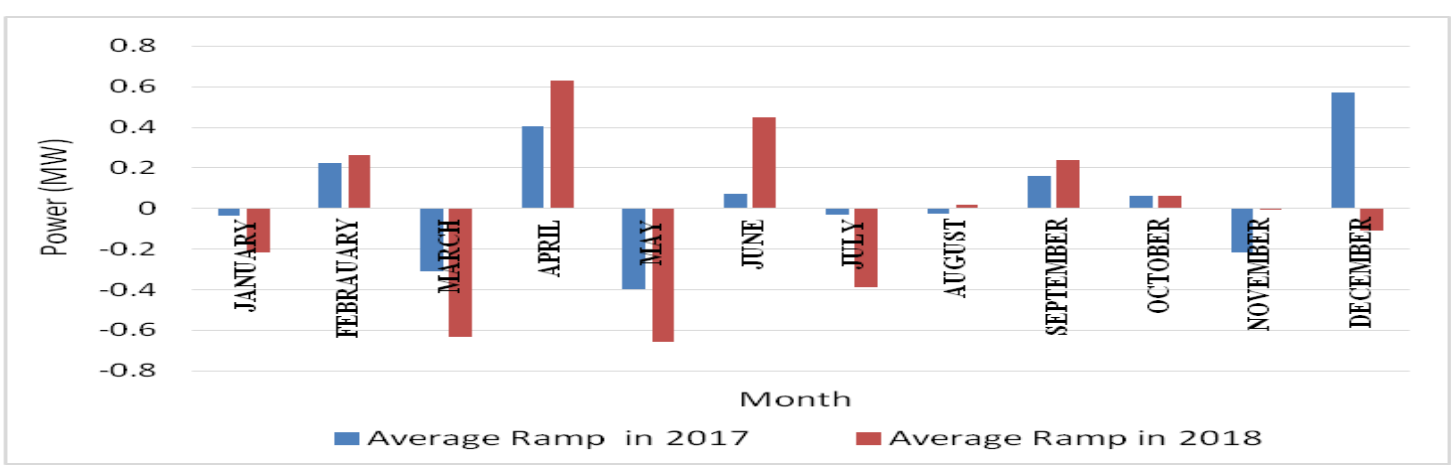

Figure 14. Comparison of the average power ramp in 15min interval for each month in 2017 and 2018.

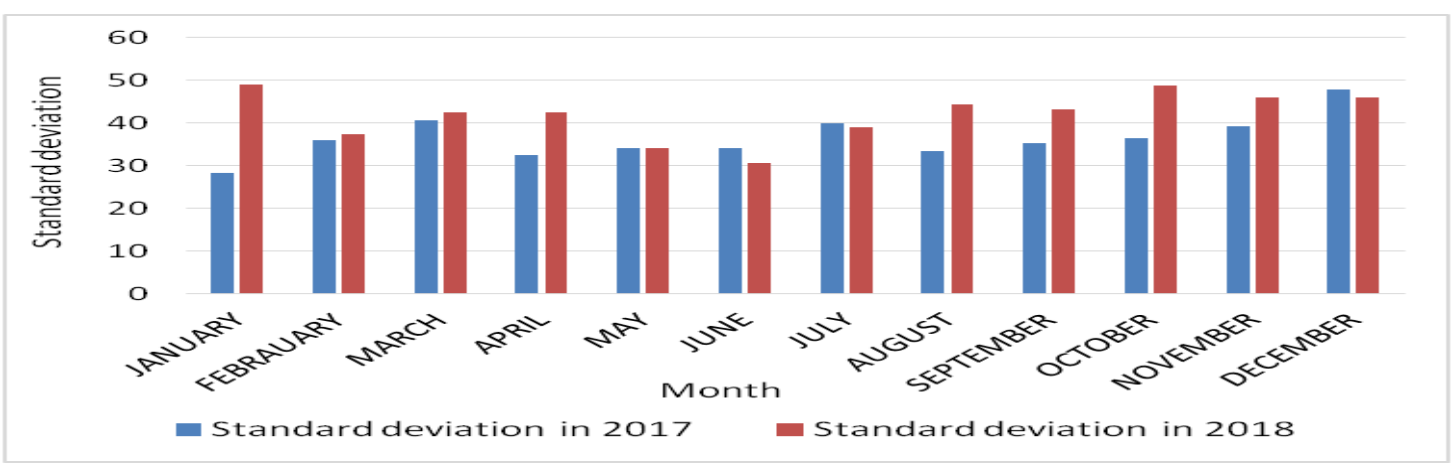

Figure 15. Comparison of the standard deviation of power ramps in $15 \mathrm{~min}$ interval for each month in 2017 and 2018.

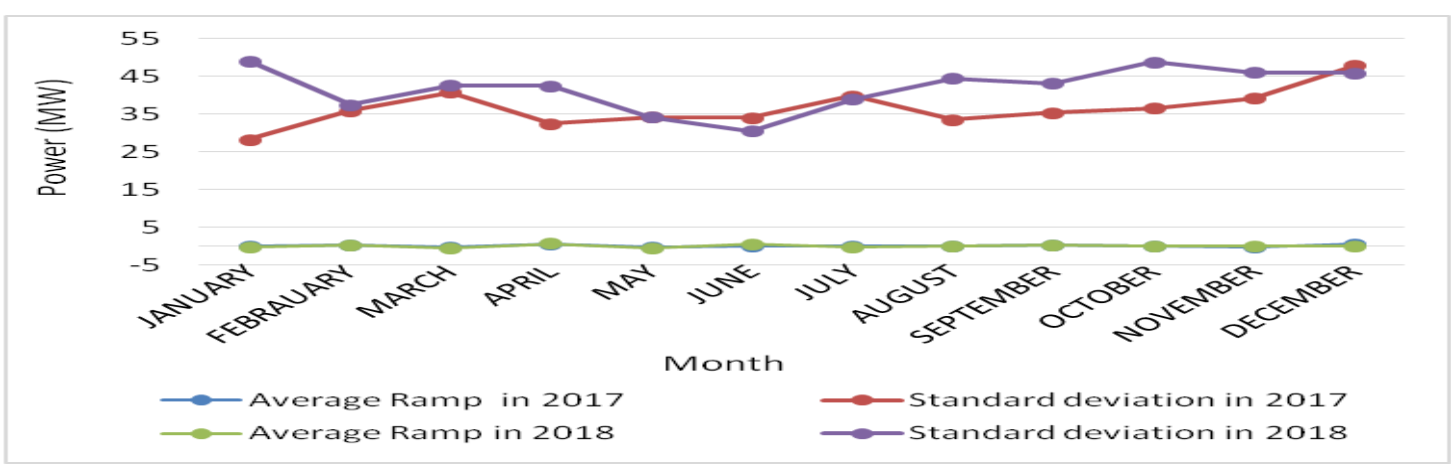

Figure 16. Comparison between the value of the standard deviation and the average value of power ramps for each month in 2017 and 2018. 


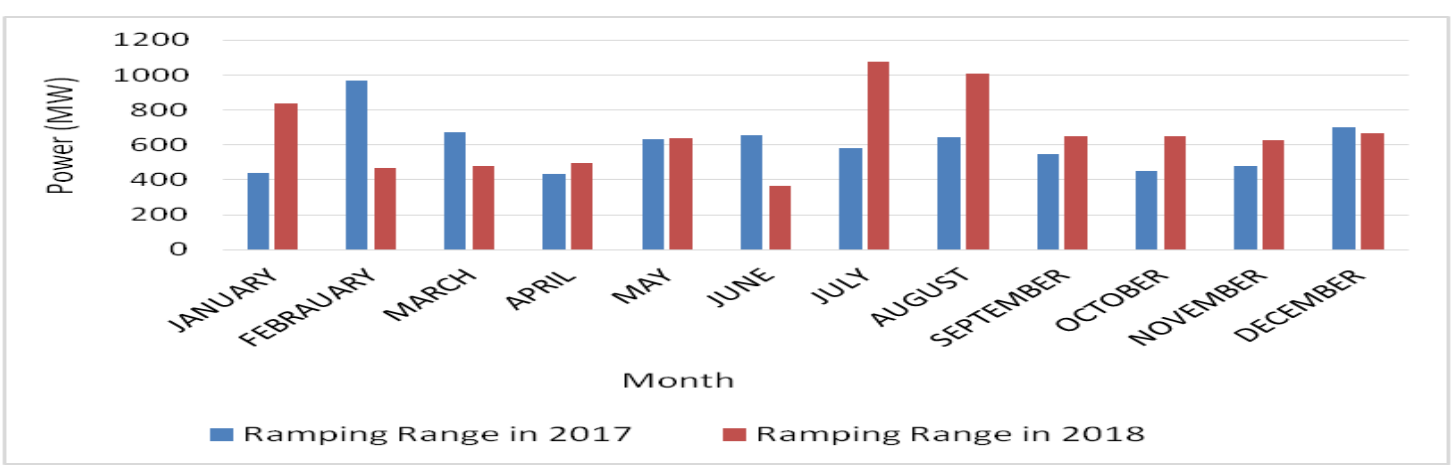

Figure 17. Comparison between ramping range of power ramps in $15 \mathrm{~min}$ interval for each month in 2017 and 2018.

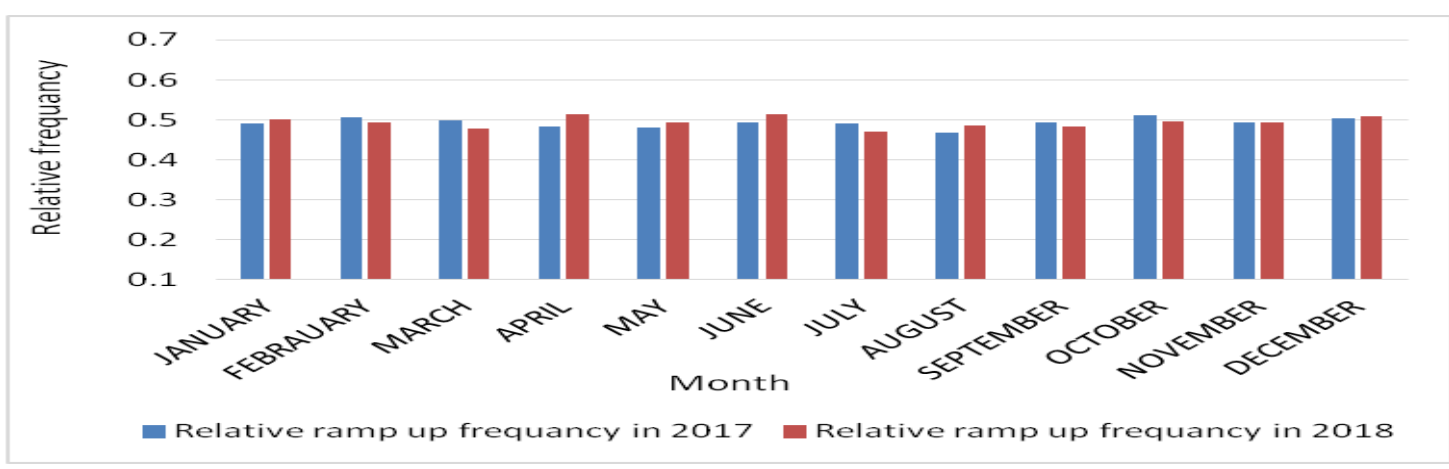

Figure 18. Comparison of the relative frequency of upward power ramps in $15 \mathrm{~min}$ interval for each month in 2017 and 2018.

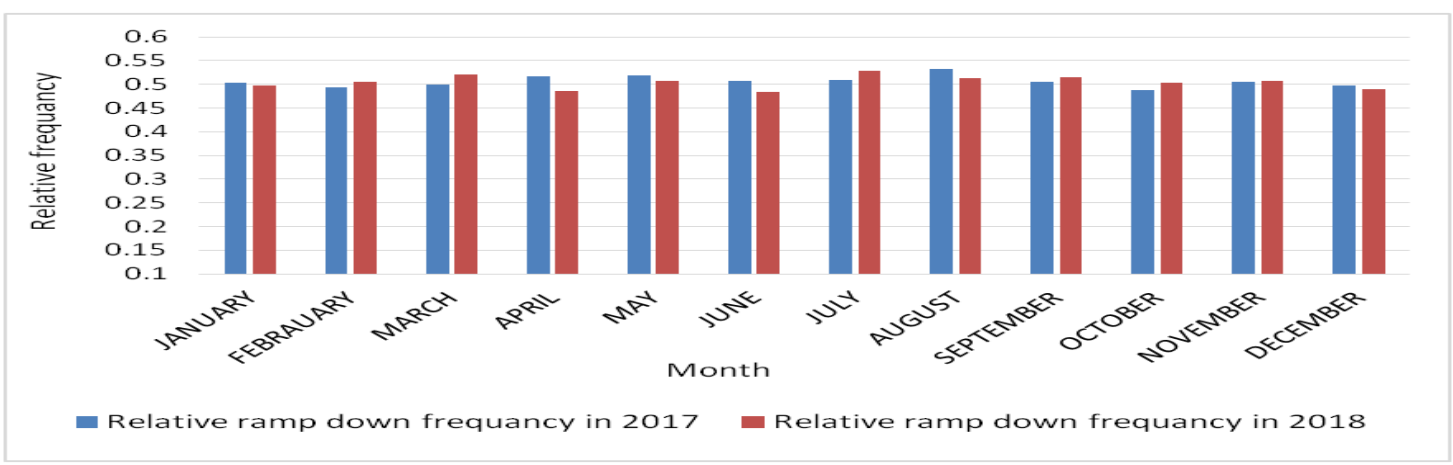

Figure 19. Comparison of the relative frequency of downward power ramps in $15 \mathrm{~min}$ interval for each month in 2017 and 2018.

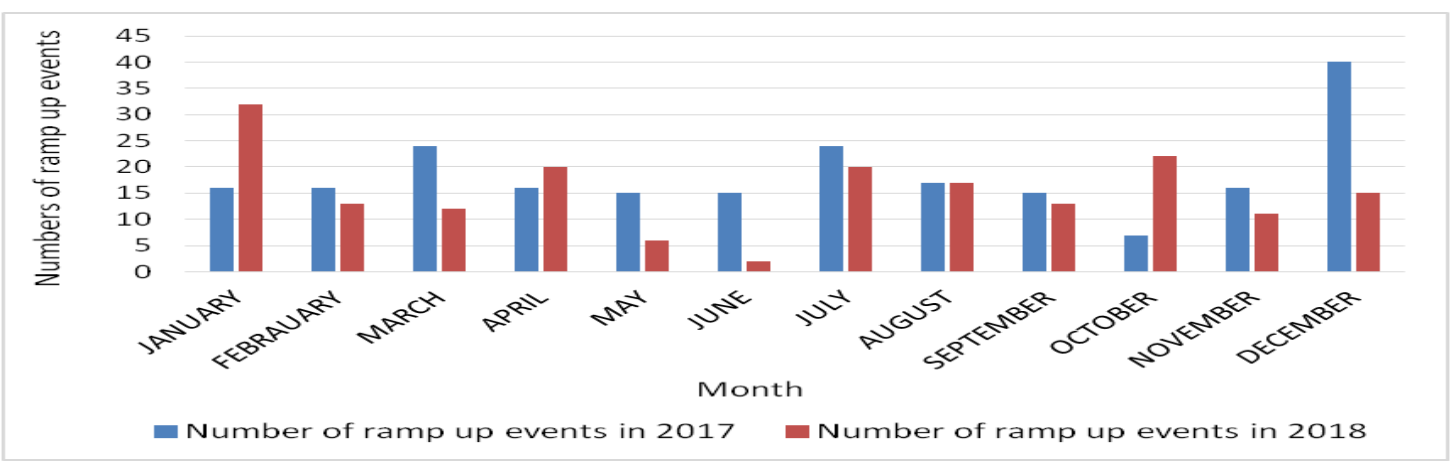

Figure 20. Comparison of the number of upward power ramp events in $15 \mathrm{~min}$ interval for each month in 2017 and 2018. 


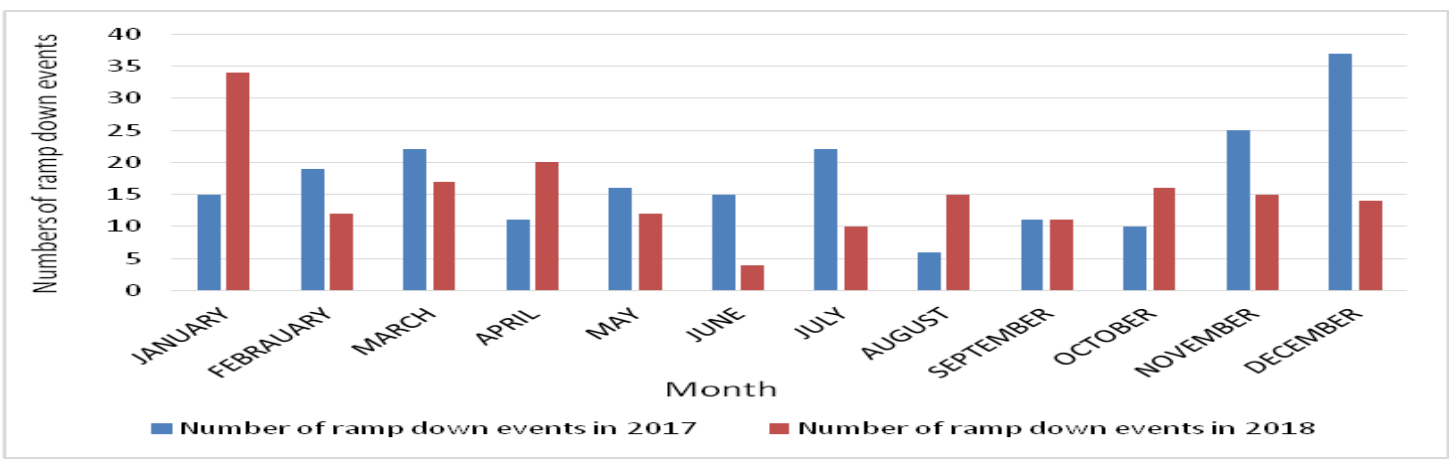

Figure 21. Comparison of the number of downward power ramp events in $15 \mathrm{~min}$ interval for each month in 2017 and 2018.

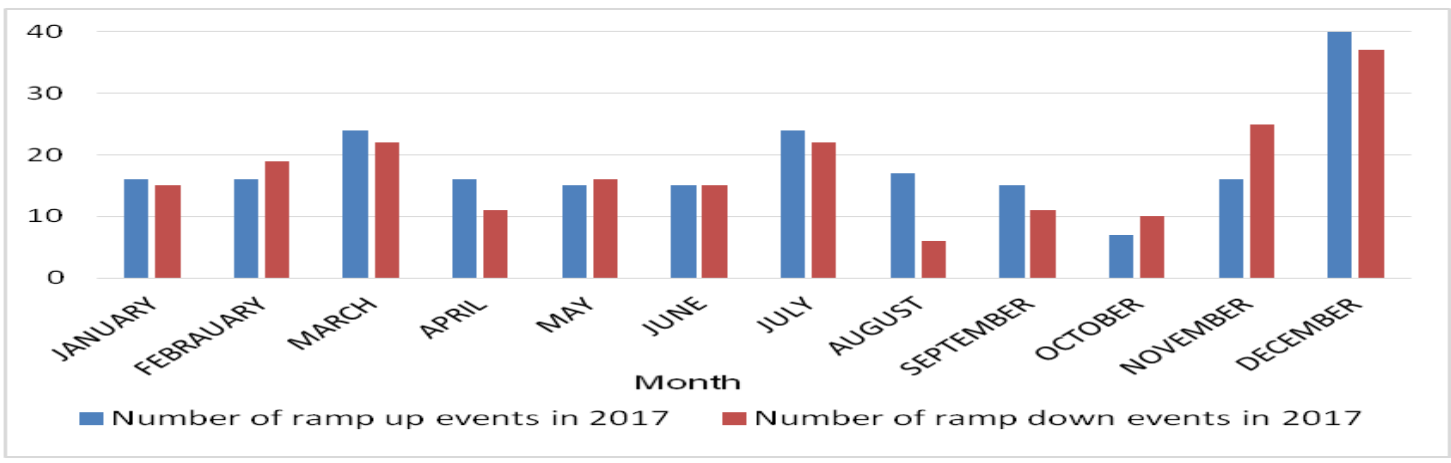

Figure 22. Comparison between the numbers of upward and downward power ramp events in $15 \mathrm{~min}$ interval for each month in 2017.

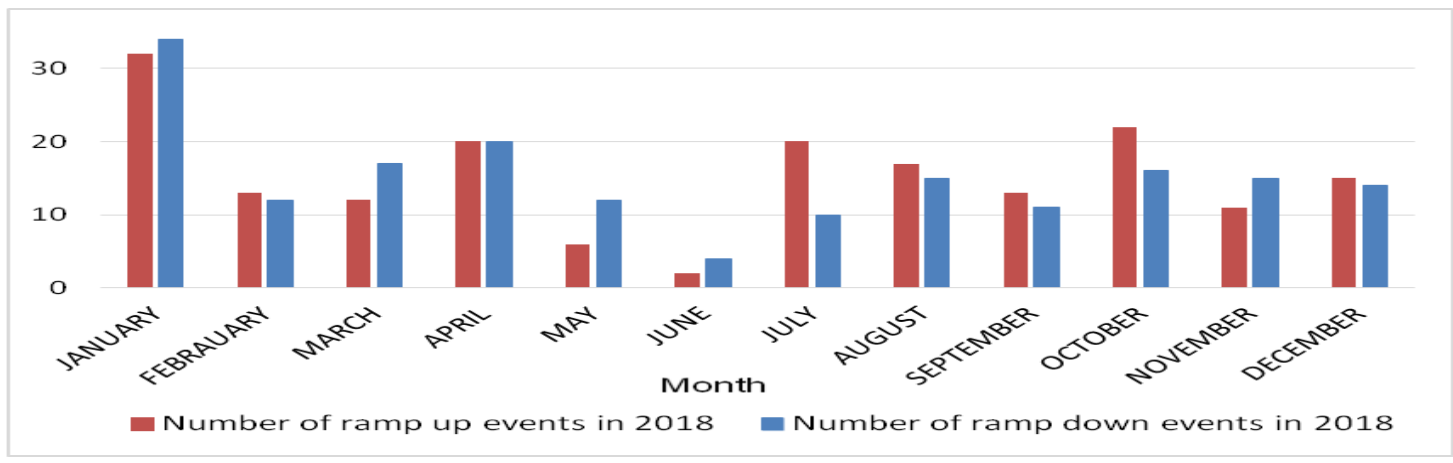

Figure 23. Comparison between the numbers of upward and downward power ramp events in $15 \mathrm{~min}$ interval for each month in 2018.

\section{CONCLUSION}

Even with hour-ahead prediction, the prediction errors of VRG still exist and the measured power ramp may be double that predicted and in the reverse direction, see Figure 1. The variations in wind speed and solar irradiance can not fully reflect the power variability. As a result, with an increase in the share of VRG, these prediction errors will greatly affect the balance of generation and consumption. Digitization of power systems brings big data which opening opportunities for improving the efficiency of power system operation. Hence, studying the power ramps of VRG in the system is necessary for the system operators to gain details about the scale of power ramps, whether they are up or down, and also the time periods in which ramp events are likely to occur. According to these data, the system operator will take the necessary precautions for balancing these ramp events, in case of a large forecasting error. The necessary precautions include a reassessment of generation reserves, dispatching or committing flexible generators that have high ramping capability, fast response, low minimum stable operation level, quick start-up and turn off capability on behave of VRG to overcome variability. 
The definition of ramp event differs from one system to the other, as it represents the amount of power change that is difficult to be managed in a certain time period. Hence, there is no agreement on a unified definition of power ramp event, where the threshold magnitude of power ramp event, expressed as a percentage of the rated power, ranged from $1 \%$ to $75 \%$, while the threshold duration extended from 5 minutes to 6 hours. Accordingly, the definition of ramp event is an extremely case-dependent issue.

In this the paper, an analysis method that depends on obtaining information from the available big data has been presented. The extracted information gives the power system operators details about the power ramping features that can be used beside the forecasted data in the system operation. The analysis method can be used to obtain the power ramping features in renewable generation, load or net load. In this method, the historical data analysis of the power-time curve is divided into two directions: vertical and horizontal. In the vertical direction, the ramping features within the studied time interval $\Delta \mathrm{t}$ at each observation time (t) on the power-time curve can be obtained. While in the horizontal direction, the ramping features within the studied time interval $\Delta \mathrm{t}$ in certain weeks, months, seasons or years can be obtained. The studied time interval $\Delta t$ is selected by the system operator according to the stage of operation to be studied. The advantage of this methodology is that it produces directly valuable information to the power system operators that can be used beside that forecasted in reducing the cost and difficulty of absorbing the variability.

The analysis method has been verified through comparing the results of analyzing the historical power data of aggregated Belgium's wind farms in 2017 and 2018 within a studied time interval of 15 min. The results of the two analysis directions outlined at each observation time and for each month the range of maximum upward and downward power ramps, the average values and the standard deviation of power ramps, the ramping range and the number of upward and downward ramp events. The results revealed that the average value of power ramps is very small compared to the standard deviation, so it should not be used to describe the actual variability in wind power. Additionally, while the variability of wind power is difficult to be forecasted with high accuracy, it is possible to determine the extent of these changes even with the increase in the rate of wind energy participation in the power system, as it has been found that there are fixed proportions of these changes when compared to the average wind capacity installed in the power system, see Figure 24, 25; as the application of the proposed analysis method to the historical data of wind power showed that the following values are approximately equal in the two years when each value was divided by the average wind capacity installed in its year and these values are:

- The average values of maximum upward and downward power ramps.

- The magnitude and direction of the average value of power ramps.

- The average value of the standard deviations.

- The average value of power ramping range.

- The average relative frequencies of upward and downward power ramps

The results also showed that the average number of ramp events, whether up or down, decreased while the percentage of installed wind capacity increased, and the average number of upward and downward ramp events are approximately equal for each year but the events of the ramp-up are a little more than down, see Figure 26, 27. In addition, the relative frequency of upward power ramps is more than downward in the period from 11 AM to $11 \mathrm{PM}$; whereas the opposite occurs between 11 PM to 11 AM, see Figures 8, 9.

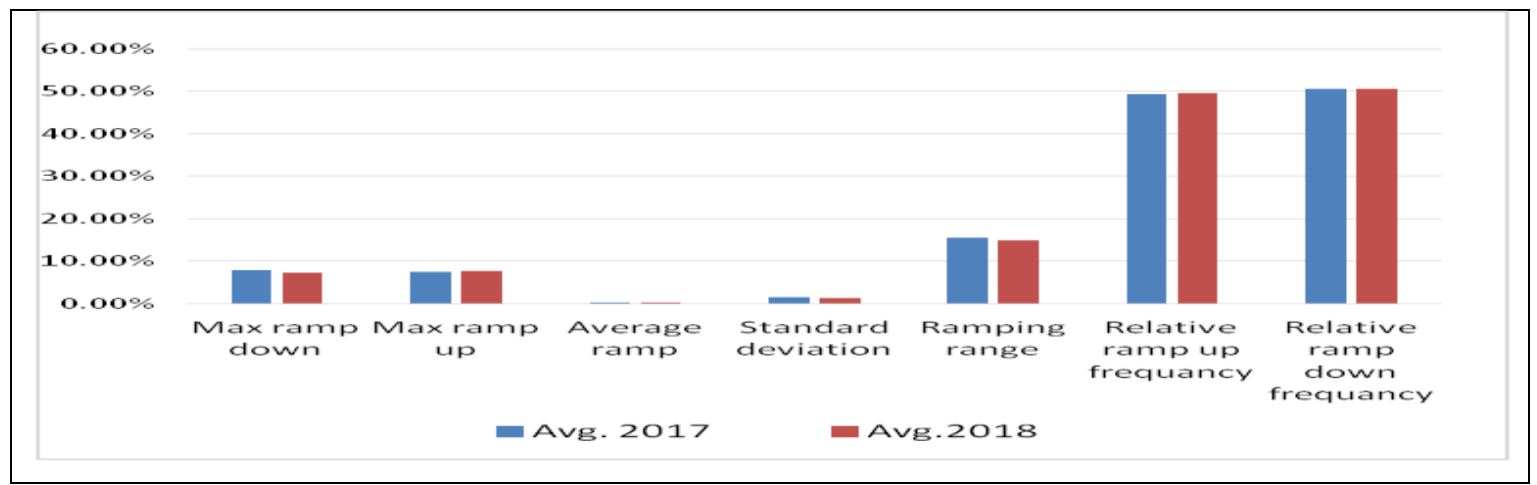

Figure 24 Comparison between average ramp values of the maximum ramp down, maximum ramp up, average ramp, standard deviation, ramping range, relative ramp up and down frequency across all observation times as a percentage for years 2017 and 2018 


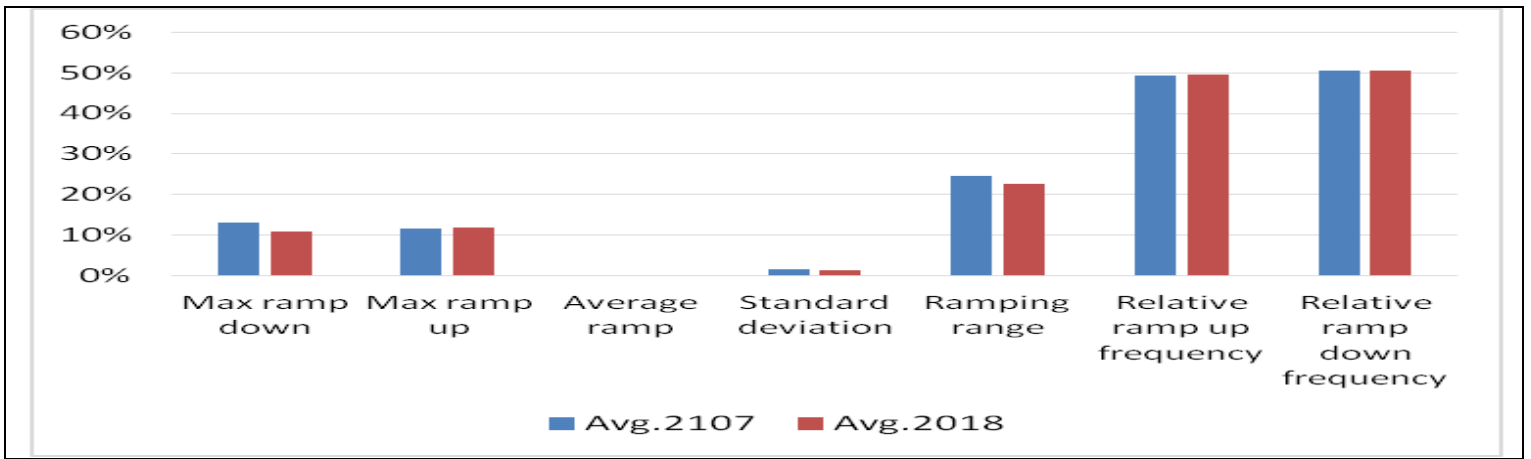

Figure 25 Comparison between the average ramp values of the maximum ramp down, maximum ramp up, average ramp, standard deviation, ramping range, relative ramp up and down frequency across all months as a percentage for years 2017 and 2018

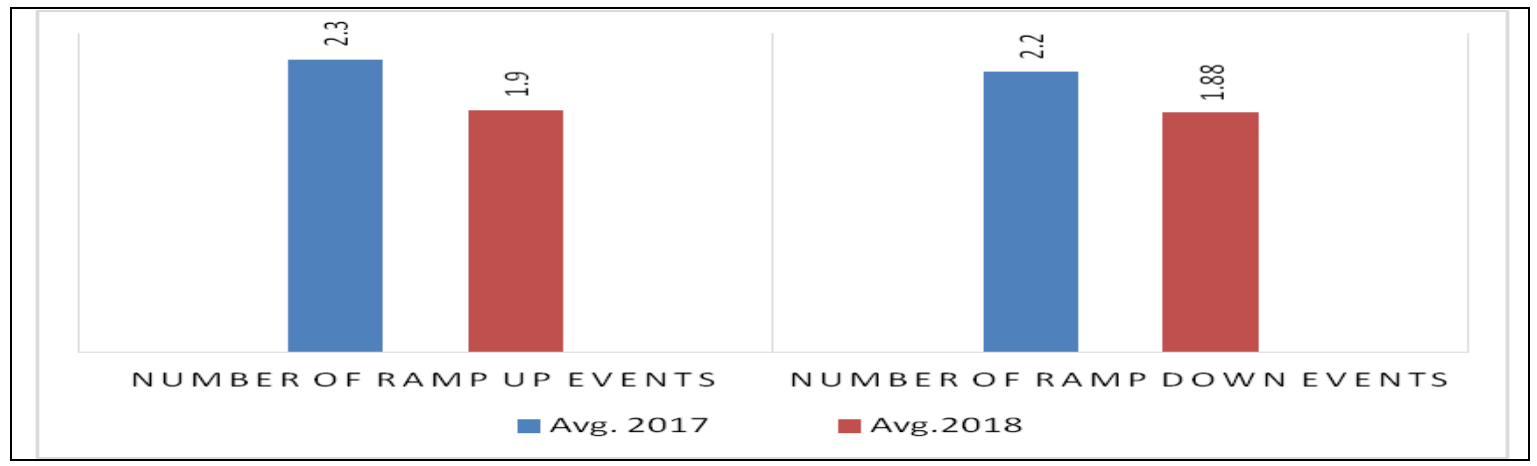

Figure 26. Comparison between the average number of ramp-up and down events in 15 min interval for each observation time $\mathrm{t}$ for years 2017 and 2018 using vertical analysis

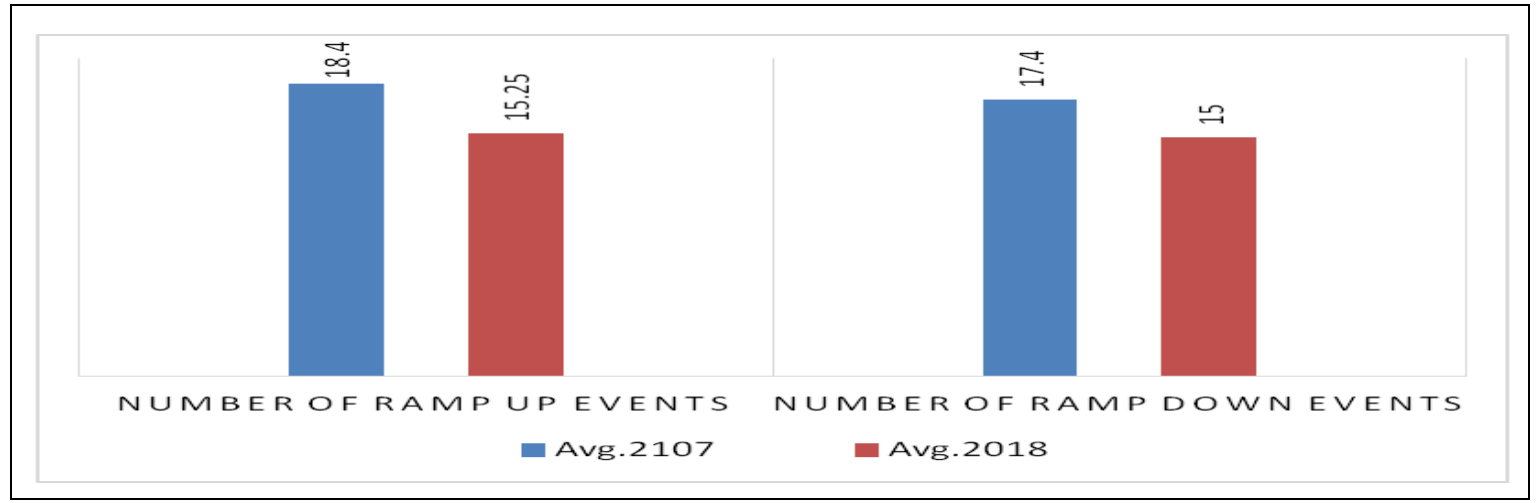

Figure 27. Comparison between the average number of ramp-up and down events in 15 min interval for each month for years 2017 and 2018 using horizontal analysis

\section{REFERENCES}

[1] J. Bertsch, C. Growitsch, S. Lorenczik, and S. Nagl, "Study on flexibility options in European electricity markets in high RES-E scenarios," no. October, pp. 1-88, 2012.

[2] M. S. Eltohamy, M. S. A. Moteleb, H. Talaat, F. S. Mekhamer, and W. Omran, "Power System Flexibility Metrics Review with High Penetration of Variable Renewable Generation,” Int. J. Inf. Technol. Appl., vol. 8, no. 1, pp. 2146, 2019.

[3] International Energie Agency, "Variability of Wind Power and Other Renewables Management options and strategies," Energy, vol. 36, pp. 1-57, 2005, [Online]. Available: http://www.iea.org/papers/2005/variability.pdf.

[4] M. S. Eltohamy, M. S. A. Moteleb, H. Talaat, S. Mekhamer, and O. Walid, "Technical Investigation for Power System Flexibility," in 6th International Conference on Advanced Control Circuits and Systems (ACCS) \& 2019 5th International Conference on New Paradigms in Electronics \& information Technology (PEIT), 2019, pp. 299309, doi: 10.1109/ACCS-PEIT48329.2019.9062862. 
[5] E. Lannoye, D. Flynn, and M. O'Malley, "The role of power system flexibility in generation planning," IEEE Power Energy Soc. Gen. Meet., no. July, 2011, doi: 10.1109/PES.2011.6039009.

[6] E. Lannoye, D. Flynn, and M. O’Malley, "Evaluation of power system flexibility," IEEE Trans. Power Syst., vol. 27, no. 2, pp. 922-931, 2012, doi: 10.1109/TPWRS.2011.2177280.

[7] Y. Wan, "Analysis of Wind Power Ramping Behavior in ERCOT," 2011. [Online]. Available: http://www.nrel.gov/wind/systemsintegration/pdfs/2011/wan_wind_power_ramping.pdf.

[8] J. Kiviluoma, H. Holttinen, D. Weir, R. Scharff, and L. Söder, "Variability in large-scale wind power generation," Wind Energy, vol. 18, no. 11, pp. 1649-1665, 2015, doi: 10.1002/we.

[9] D. A. Halamay and T. K. A. Brekken, "A Methodology for Quantifying Variability of Renewable Energy Sources by Reserve Requirement Calculation,”pp. 666-673, 2010.

[10] I. Würth et al., "Minute-scale forecasting of wind power-results from the collaborative workshop of IEA Wind task 32 and 36," Energies, vol. 12, no. 4, 2019, doi: 10.3390/en12040712.

[11] A. A. Thatte and L. Xie, "A metric and market construct of inter-temporal flexibility in time-coupled economic dispatch," IEEE Trans. Power Syst., vol. 31, no. 5, pp. 3437-3446, 2016, doi: 10.1109/TPWRS.2015.2495118.

[12] elia and 3E, "Offshore integration study: Analysis, benchmark and mitigation of storm and ramping risks from offshore wind power in Belgium," 2018.

[13] "Elia, Belgium's electricity transmission system operator," 2019. http://www.elia.be/en/grid-data/powergeneration/wind-power (accessed Jul. 31, 2019).

[14] G. Ren, J. Wan, J. Liu, D. Yu, and L. Söder, "Analysis of wind power intermittency based on historical wind power data," Energy, vol. 150, pp. 482-492, 2018, doi: 10.1016/j.energy.2018.02.142.

[15] Y. Cui, F. Bai, Y. Liu, and D. Smith, "Statistical Characterization of Solar Irradiance Variability and Its Effect on Step Voltage Regulators," 2019 IEEE PES Innov. Smart Grid Technol. Asia, ISGT 2019, no. 1, pp. 3245-3250, 2019, doi: 10.1109/ISGT-Asia.2019.8881275.

[16] C. Gallego-Castillo, A. Cuerva-Tejero, and O. Lopez-Garcia, "A review on the recent history of wind power ramp forecasting," Renew. Sustain. Energy Rev., vol. 52, pp. 1148-1157, 2015, doi: 10.1016/j.rser.2015.07.154.

[17] M. Sherry and D. Rival, "Meteorological phenomena associated with wind-power ramps downwind of mountainous terrain,” J. Renew. Sustain. Energy, vol. 033101, no. 7, pp. 1-13, 2015, doi: 10.1063/1.4919021.

[18] AWS Truewind, "Final Report for the Alberta Forecasting Pilot Project," Alberta, Canada, 2008.

[19] C. Kamath, "Understanding Wind Ramp Events Through Analysis of Historical Data," in IEEE PES Transmission and Distribution Conference and Expo, April 20-22, 2010, pp. 1-6.

[20] A. J. Deppe, W. A. Gallus, and E. S. Takle, "A WRF Ensemble for Improved Wind Speed Forecasts at Turbine Height,” Weather Forecast., vol. 28, pp. 212-228, 2013, doi: 10.1175/WAF-D-11-00112.1.

[21] T. Ouyang, X. Zha, and L. Qin, “A Survey of Wind Power Ramp Forecasting,” Energy Power Eng., vol. 05, no. 04, pp. 368-372, 2013, doi: 10.4236/epe.2013.54B071.

[22] B. Greaves, J. Collins, J. Parkes, and A. Tindal, "Temporal Forecast Uncertainty for Ramp Events," Wind Eng., vol. 33, no. 4, pp. 309-319, 2009, doi: 10.1260/030952409789685681.

[23] C. Kamath, "Using Simple Statistical Analysis of Historical Data to Understand Wind Ramp Events," 2010, doi: 10.1109/TDC.2010.5484508.

[24] M. S. Eltohamy, M. S. A. Moteleb, H. Talaat, F. S. Mekhamer, and O. Walid, "Analyzing Wind Power Ramps for High Penetration of Variable Renewable Generation," in 2019 21st International Middle East Power Systems Conference (MEPCON), 2019, pp. 768-775, doi: 10.1109/MEPCON47431.2019.9007951.

[25] M. S. Eltohamy, M. S. A. Moteleb, H. Talaat, S. Mekhamer, and W. Omran, "Overview of Power System Flexibility Options with Increasing Variable Renewable Generations," in 6th International Conference on Advanced Control Circuits and Systems (ACCS) \& 2019 5th International Conference on New Paradigms in Electronics \& information Technology (PEIT), 2019, pp. 280-292, doi: DOI: 10.1109/ACCSPEIT48329.2019.9062836.

[26] M. Cui, J. Zhang, C. Feng, A. R. Florita, Y. Sun, and B. M. Hodge, "Characterizing and analyzing ramping events in wind power, solar power, load, and netload," Renew. Energy, vol. 111, pp. 227-244, 2017, doi: 10.1016/j.renene.2017.04.005.

[27] W. J. Ferreira C, Gama J, Matias L, Botterud A, "A survey on wind power ramp forecasting," Argonne Natl. Lab.(ANL), Argonne, (United States), 2011.

[28] D. Gan and D. Ke, "Wind Power Ramp Forecasting Based on Least-Square Support Vector Machine," Energy Eng. Environ. Eng., vol. 535, pp. 162-166, 2014, doi: 10.4028/www.scientific.net/AMM.535.162. 


\section{BIOGRAPHY OF AUTHORS}

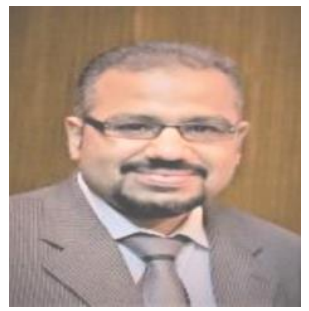

Mohammed Saber Eltohamy Research Assistant at Department of Power Electronics and Energy Conversion, Electronics Research Institute. He received the B.Sc. degree from Faculty of Engineering at Shoubra, Benha University in 2004, and the M.Sc. degree in electrical engineering from Cairo University in 2014. He is a Ph.D. student at Ain Shams University, Cairo, Egypt. His research interests include Planning and Operation of Power Systems, Integration of Renewable Energy Systems, Distributed Generation, and Energy Management. Email: mohammed_saber@eri.sci.eg

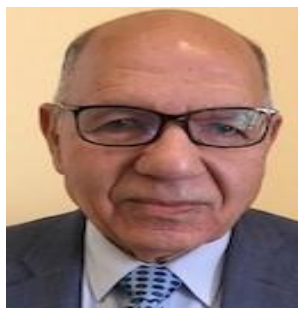

Mohammed Said Abdel Moteleb Professor at Department of Power Electronics and Energy Conversion, Electronics Research Institute. He received his B.Sc. And M.Sc. degrees from Cairo University, Cairo, Egypt in 1971 and 1978 respectively, and his Ph.D. degree from the Faculty of electrical Engineering and information technology, Slovak Technology University, Slovakia in 1986. Prof. Moteleb is one of the leading editors-in-chief of the journal of electrical systems and information technology. His research interests include Control of Energy Systems and Optimization Techniques.

Email: moteleb@eri.sci.eg

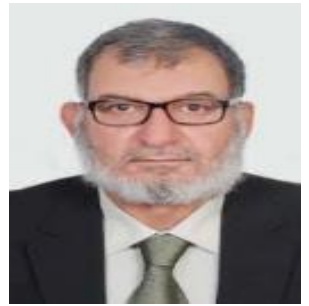

Hossam Talaat Professor at the Electrical Engineering Department at Future Univerity in Egypt. $\mathrm{He}$ was the former Head of the Electrical Power Engineering Department, Faculty of Engineering, Ain Shams University, Cairo, Egypt. He received his B.Sc. And M.Sc. degrees from Ain Shams University, Cairo, Egypt in 1975 and 1980 respectively, and his Ph.D. degree from University of Grenoble, France in 1986. His research interests include: Distributed Generation and Microgrids, Application of artificial intelligence techniques to Power System analysis, control, and protection; Real time applications to electrical power systems and machines; Application of optimal and adaptive control techniques.

Email: hossam.eldeen@fue.edu.eg

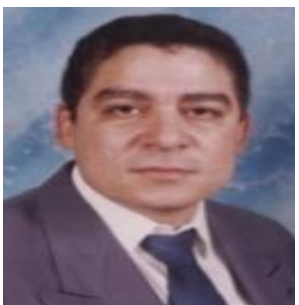

Said Fouad Mekhemar received the B.Sc. degree in electrical engineering from Ain Shams University, Cairo, Egypt, in 1993, and the Ph.D. degree from the Dalhousie University, Canada, in 2002. He is currently a Professor at the Electrical Engineering Department at Future Univerity in Egypt.

Email: said_fouad@eng.asu.edu.eg

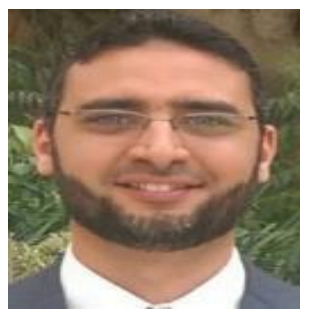

Walid A. Omran received the B.Sc. and M.Sc. degrees in electrical engineering from Ain Shams University, Cairo, Egypt, in 1998 and 2005, respectively, and the Ph.D. degree from the Department of Electrical and Computer Engineering, University of Waterloo, Canada, in 2010. Currently, he is an associate professor at the Future University of Egypt (on leave from Ain Shams University). His research interests include planning and operation of smart grids, integration of renewable energy systems and energy storage systems.

Email: walid.omran@fue.edu.eg 